NBER WORKING PAPER SERIES

\title{
BIDDING WITH SECURITIES: AUCTIONS AND SECURITY DESIGN
}

\author{
Peter M. DeMarzo \\ Ilan Kremer \\ Andrzej Skrzypacz \\ Working Paper 10891 \\ http://www.nber.org/papers/w10891
}

\author{
NATIONAL BUREAU OF ECONOMIC RESEARCH \\ 1050 Massachusetts Avenue \\ Cambridge, MA 02138 \\ November 2004
}

\begin{abstract}
We thank Kerry Back, Simon Board, Burton Hollifield, John Morgan and seminar participants at HBS, Iowa, NYU, Stanford, U.C. Berkeley, U.C. Davis, U.C. San Diego, Washington University, WFA 2003 and the Utah Winter Finance Conference 2004 for useful comments. This material is based upon work supported by the National Science Foundation under Grant No. 0318476. The views expressed herein are those of the author(s) and not necessarily those of the National Bureau of Economic Research.
\end{abstract}

(C) 2004 by Peter M. DeMarzo, Ilan Kremer, and Andrzej Skrzypacz. All rights reserved. Short sections of text, not to exceed two paragraphs, may be quoted without explicit permission provided that full credit, including () notice, is given to the source. 
Bidding with Securities: Auctions and Security Design

Peter M. DeMarzo, Ilan Kremer, and Andrzej Skrzypacz

NBER Working Paper No. 10891

November 2004

JEL No. D4, G3

\begin{abstract}
We study security-bid auctions in which bidders compete by bidding with securities whose payments are contingent on the realized value of the asset being sold. Such auctions are commonly used, both formally and informally. In formal auctions, the seller restricts bids to an ordered set, such as an equity share or royalty rate, and commits to a format, such as first or second-price. In informal settings with competing buyers, the seller does not commit to a mechanism upfront. Rather, bidders offer securities and the seller chooses the most attractive bid, based on his beliefs, ex-post.
\end{abstract}

We characterize equilibrium payoffs and bidding strategies for formal and informal auctions. For formal auctions, we examine the impact of both the security design and the auction format. We define a notion of the steepness of a set of securities, and show that steeper securities lead to higher revenues. We also show that the revenue equivalence principle holds for equity and cash auctions, but that it fails for debt (second-price auctions are superior) and for options (a first-price auction yields higher revenues). We then show that an informal auction yields the lowest possible revenues across all possible formal mechanisms. Finally, we extend our analysis to consider the effects of liquidity constraints, different information assumptions, and aspects of moral hazard.

Peter M. DeMarzo

Graduate School of Business

Stanford University

Stanford, CA 94305

and NBER

pdemarzo@stanford.edu

Ilan Kremer

Stanford University

kremer_ilan@gsb.stanford.edu
Andrzej Skrzypacz

Stanford University

skrzypacz_andrzej@gsb.stanford.edu 


\section{Introduction}

Auction theory and its applications have become increasingly important as an area of economic research over the last twenty years. As a result, we now have a better understanding of how the structure of an auction affects its outcome. Almost all the existing literature studies the case when bidders use cash payments, so that the value of a bid is not contingent on future events.

In a few cases, such as art auctions, the realized value is subjective and cannot be used as a basis for payment; however, this is the exception. In many important applications, the realization of the future cash flow generated by the auctioned asset or project can be used in determining the actual payment. That is, the bids can be securities whose values are derived from the future cash flow. We call this setting a security-bid auction, and provide an extensive characterization of such auctions.

Formal auctions of this type are commonly used in government sales of oil leases, wireless spectrum, highway building contracts, and lead-plaintiff auctions. Informal auctions of this type (in the sense that formal auction rules are not set forth in advance) are common in the private sector. Examples include authors selling publishing rights, entrepreneurs selling their firm to an acquirer or soliciting venture capital, and sports associations selling broadcasting rights. ${ }^{1}$

The major difference between a formal and an informal mechanism is the level of commitment by the seller. In an informal mechanism, bidders choose which securities to offer, and the seller selects the most attractive offer ex-post. In this case, the auction contains the elements of a signaling game because the seller may infer bidders' private information from their security choices when evaluating their offers. In a formal mechanism the seller restricts bidders to use securities from a pre-specified ordered set, such as an equity share or royalty rate. The seller is committed to disqualify any offer outside this set. The seller also commits to an auction format, such as a first or secondprice auction. One of our main results is that the revenues from an informal mechanism are the lowest across a large set of possible mechanisms. In other words, the seller benefits from any form of commitment. Moreover, we show how to rank security designs and auction formats in terms of their impact on the seller's revenues and that the design of the securities can be more important than design of the auction itself.

In our model, several agents compete for the right to undertake a project that requires an upfront investment. Bidders are endowed with private signals regarding the value they can expect from the project. Our initial structure is similar to an independent private values model, so that different bidders expect different payoffs upon winning, though we also consider correlated and common values. The model differs from standard auction

\footnotetext{
${ }^{1}$ See Hendricks and Porter (1988) for a discussion of oil lease auctions, in which royalty rates are commonly used. In wireless spectrum auctions, the bids are effectively debt securities (leading in some cases to default). Highway building contracts are often awarded through "build, operate, and transfer" agreements to the bidder that offers to charge the lowest toll for a pre-specified period. See Fisch (2001) for the use of contingency-fee auctions in the selection of the lead plaintiff in class action suits. In mergers, acquisitions and venture capital agreements, equity and other securities are commonly used (see Martin (1996)). McMillan (1991) describes the auction of the broadcast rights to the Olympic games, where bids contained revenue-sharing clauses. Similarly, publishing contracts include advance and royalty payments.
} 
models, in that bids are securities. Bidders offer derivatives in which the underlying value is the future payoff of the project. Because the winner may make investments or take other actions that affect this future payoff, we also discuss the possibility of moral hazard.

One might conjecture that the results from standard auction theory carry over to securitybid auctions by simply replacing each security with its cash value. However, unlike cash bids, the value of a security bid depends upon the bidder's private information. This difference can have important consequences as the following simple example demonstrates:

Consider an auction in which two bidders, Alice and Bob, compete for a project. The project requires an initial fixed investment that is equivalent to $\$ 1 \mathrm{M}$. Alice expects that if she undertakes the project then on average it would yield revenues of $\$ 3 \mathrm{M}$; Bob expects that future revenues will equal only $\$ 2 \mathrm{M}$. Hence, Alice sees a profit of $\$ 2 \mathrm{M}$ while Bob sees a profit of $\$ 1 \mathrm{M}$. Assuming these estimates are private values, in a standard second-price auction it is a dominant strategy for bidders to bid their reservation values. As a result, Alice would win the auction and pay Bob's bid, $\$ 1 \mathrm{M}$.

Now suppose that rather than bidding with cash, the bidders compete by offering a fraction of the future revenues. As we later discuss, it is again a dominant strategy for bidders to bid their reservation values. Alice offers $2 / 3$ of future revenues while Bob offers $1 / 2$. As a result, Alice wins the auction and pays according to Bob's bid; that is, she gives up one-half of the future revenues. This yields a higher payoff for the auctioneer; $(1 / 2) \times \$ 3 \mathrm{M}=\$ 1.5 \mathrm{M}>\$ 1 \mathrm{M}$.

This example is based on Hansen (1985), who was the first to examine the use of securities in an auction setting. Hansen showed that a second-price equity auction yields higher expected revenues than a cash-based auction. In a related paper, Riley (1988) considers first-price auctions where bids include royalty payments in addition to cash. He shows that adding the royalty increases expected revenues. The intuition in both cases is that adding an equity component to the bid lowers the difference between the winner's valuation and that of the second highest bidder. Because this difference is the rent captured by the winner, reducing it benefits the seller.

In this paper, we generalize this insight along several dimensions. First, we consider a general class of securities that includes debt, equity or royalty rates, options, and hybrids of these. Second, we consider alternative auction formats (e.g., first-price vs. secondprice). Third, we consider informal auctions, in which the seller cannot commit to an auction mechanism in advance.

The structure of the paper is as follows. The basic model is described in Section 2. We begin our analysis in Section 3 by examining formal mechanisms, which consist of both an auction format and a security design. There we establish the following results:

- We characterize super-modularity conditions under which a monotone - and hence efficient - equilibrium is the unique outcome for the first and second-price auctions.

- First we compare security designs holding fixed the auction format (first or second-price). We show that for either format, the seller's expected revenues are 
positively related to the "steepness" (a notion that we define) of the securities. As a result, debt contracts minimize the seller's expected payoffs while call options maximize it. This result generalizes the observations of Hansen (1985) and Riley (1988).

- Fixing the security design, we then consider the role of the auction format. We define two important classes of sets of securities: sub-convex and super-convex sets For sub-convex sets - which include, for example, the set of debt securities we show that a second-price auction yields higher expected revenues than a firstprice auction. Alternatively, if the set is super-convex (e.g., call options), the reverse conclusion holds and first-price auctions are superior. However, we find the effect of the auction format to be small relative to the security design.

- We then ask whether the Revenue Equivalence principle for cash auctions, which states that expected revenues are independent of the auction format, can be extended to security bid auctions. We show it holds if the ordered set of securities is convex. This is true for important classes of securities, such as equity.

- Finally we combine these results to show that the first-price auction with call options maximizes the seller's revenue, while the first-price format with debt minimizes it, over a general set of auction mechanisms.

In the second part of the paper (Section 4), we consider the case in which the seller is unable to commit ex-ante to a formal auction mechanism. Instead he accepts all bids and chooses the security that is optimal ex-post. Though often not labeled as "auctions" because they lack a formal mechanism, we believe that these informal auctions represent the vast majority of auction-like activity in practice, since in most transactions the seller is unable to commit to a decision rule ex-ante. As mentioned above, in this case the task of selecting the winning bid is not trivial; it involves a signaling game in which the seller uses his beliefs to rank the different securities and choose the most attractive one. Our main result is as follows:

- In the unique equilibrium satisfying standard refinements of off-equilibrium beliefs, bidders use only debt securities. Moreover, the outcome is equivalent to a first-price auction. As a result we conclude that this ex-post maximization yields the worst possible outcome for the seller!

The intuition is that debt provides the cheapest way for a high type to signal his quality. Thus, bidders find it optimal to compete using debt.

Section 5 extends the model by considering the effects of: relaxing liquidity constraints, moral hazard regarding the bidder's investment, reservation prices, and the introduction of affiliated as well as common values. We demonstrate that the main insights of our analysis carry over to these settings. For example, we show that:

- If the bidder's investment in the project is unverifiable and subject to moral hazard, then it is not optimal for the seller to offer cash compensation to the winner for this investment.

- Combining cash payments with bids effectively "flattens" the bids and reduces the expected revenues of the seller. 
- Our conclusions regarding the revenue consequences of the security design carry over to the case of affiliated values with both private and common components.

Section 6 concludes and the Appendix contains proofs omitted in the text.

\section{Related Literature}

As mentioned above, Hansen (1985) and Riley (1988) first demonstrated the potential advantages of equity versus cash auctions. In a more recent paper, Rhodes-Kropf and Viswanathan (2000) focus on first-price auctions in a setting that is similar to the model we study in the first part of the paper, and show that securities yield higher revenues than a cash-based auction. However, none of these papers provides a general means of comparing sets of non-linear securities, as we do here. Nor do they compare auction formats or consider informal auctions. Finally, the results in Riley (1988) and RhodesKropf and Viswanathan (2000) are conditional upon the existence of a separating equilibrium in which a higher type bids a higher security. For example in Rhodes-Kropf and Viswanathan (2000), there always exists a pooling equilibrium and in some cases it is the unique outcome. This is because they assume that the project does not require any costly inputs - thus the lowest type can offer $100 \%$ of the proceeds to the seller and breakeven. Thus, a low type is always willing to imitate the bid of a high type. We use a framework that is closer to Hansen (1985), in which the project requires costly inputs. In this case, we show that under certain conditions the first-price auction has a unique equilibrium, and it is separating.

One reason security-bid auctions may not have received greater attention in the literature is perhaps due to Cremer (1987), who argues that the seller can extract the entire surplus if he can "buy" the winning bidder. Specifically, the seller can offer cash to the bidder to cover the costs of any required investment, and ask all bidders to reveal their type. The seller then offers the project to highest type in exchange for its full value. Since bidders earn zero profits regardless, truthful reporting is incentive compatible.

In the first part of the paper, we rule out such reimbursement by assuming the seller is cash constrained. Moreover, we show in Section 5 that even if the seller is not cash constrained, reimbursing the winning bidder is extremely fragile to the introduction of moral hazard. If the bidder's investment is not verifiable and reimbursement were offered, then all bidders would claim the highest type, collect the reimbursement, and then fail to invest in the project. Thus, to insure that bidders invest, the seller will only offer compensation that is contingent on the outcome of the project. Thus Cremer's approach is infeasible and the issue of security and auction design remains relevant. ${ }^{2}$

Board (2002), Che and Gale (2000), Rhodes-Kropf and Viswanathan (2002), and Zheng (2001) consider auctions with financially constrained bidders who use debt, or external financing, in their bids. Hence, while bids maybe expressed in terms of cash, they are in fact contingent claims and are thus examples of the security-bids that we examine here.

Garmaise (2001) studies a security-bid auction in the context of a financing problem for an entrepreneur. The entrepreneur commits to rank securities according to some

\footnotetext{
${ }^{2}$ Samuelson (1987) points to some additional problems in the implementation of the Cremer mechanism as it may yield an inefficient choice of a winning bidder.
} 
announced beliefs regarding the distribution of the cash flows. He examines a common value environment and obtains a partial characterization of the equilibrium in a binary model (two bidders, two types, two values).

Other related literature includes McAfee and McMillan (1987), who solve for the optimal mechanism in a model with a moral hazard problem. The optimal mechanism is a combination of debt and equity, with the mixture depending on the distribution of types. Laffont and Tirole (1987) examine a similar model. Board (2004) analyzes selling real options to competing buyers. The seller offers a mechanism in which payments have two components: unconditional and conditional on exercising the option. After the auction the winner learns more about the profitability of the option and decides whether to exercise it. For a given contract, higher types have a higher probability of exercising and hence higher expected total payments. That linkage increases seller's share of the expected surplus. Unlike our paper, contingent payments also create an inefficiency as the winner is not a full residual claimant and hence will not always exercise efficiently.

Some of our results are also related to the security design literature. DeMarzo and Duffie (1999) consider the ex-ante security design problem faced by an issuer who will face a future liquidity need. They show that debt securities are optimal because they have the greatest liquidity. DeMarzo (2002) extends this result to the case in which the issuer learns his private information prior to the design of the security, as is the case here. The security design results of this paper are also related to the results of Nachman and Noe (1994). They consider a situation in which the seller is obligated to raise a fixed amount of capital, which leads to a pooling equilibrium using debt securities. None of these models consider security design in a competitive setting like the auction environment considered here.

\section{The Model}

\section{Signals and Values}

There are $n$ risk neutral bidders who compete for the rights to a project. The project requires a non-contractible investment by the winner of $X>0$. For tractability, we assume that this cost is non-random and equal across bidders. Conditional on being undertaken by bidder $i$, the project yields a stochastic future payoff $Z_{i}$. Bidders have private signals regarding $Z_{i}$, which we denote by $V_{i}$. The seller is also risk neutral, and cannot undertake the project independently. The interest rate is normalized to zero.

We make the following standard economic assumptions on the signals and payoffs:

Assumption A. The private signals $V=\left(V_{1}, \ldots, V_{n}\right)$ and payoffs $Z=\left(Z_{1}, \ldots, Z_{n}\right)$ satisfy the following properties:

1. The private signals $V_{i}$ are i.i.d. with density $f(v)$ with support $\left[v_{L}, v_{H}\right]$.

2. Conditional on $V=v$, the payoff $Z_{i}$ has density $h\left(z \mid v_{i}\right)$ with full support $[0, \infty)$. 
3. $\left(Z_{i}, V_{i}\right)$ satisfy the strict Monotone Likelihood Ratio Property (SMLRP); that is, the likelihood ratio $h(z \mid v) / h\left(z \mid v^{\prime}\right)$ is increasing ${ }^{3}$ in $z$ if $v>v^{\prime} .4$

The important economic assumptions contained above are, first, that the private signals of other bidders are not informative regarding the signal or payoff of bidder $i$. This assumption does not imply a pure private value setting - there may be an additional common value component that is common knowledge across all bidders. Second, because $Z_{i}$ is not bounded away from zero, the project payoff cannot be used to provide a completely riskless payment to the seller. Finally, the private signal $V_{i}$ is "good news" about the project payoff $Z_{i}$ using the standard strict version of the affiliation assumption (see Milgrom and Weber (1982)).

Given the above assumptions, we normalize (without loss of generality) the private signals so that

$$
E\left[Z_{i} \mid V_{i}\right]-X=V_{i} .
$$

Thus, we can interpret the signal as the NPV of the project, which we assume to be nonnegative.

To simplify our analysis, we make several additional technical assumptions regarding differentiability and integrability:

Assumption B. The conditional density function $h(z \mid v)$ is twice differentiable in $z$ and $v$. In addition, the functions $z h(z \mid v),\left|z h_{v}(z \mid v)\right|$ and $\left|z h_{v v}(z \mid v)\right|$ are integrable on $z \in(0, \infty)$.

These assumptions are weak, and allow us to take derivatives "through" expectation operators. As a concrete example, we can consider the following payoff structure:

$$
Z_{i}=\theta\left(X+V_{i}\right)
$$

where $\theta$ is independent of $V$ and log-normal with a mean of $1 .^{5}$ Here we can interpret $\theta$ as the project risk.

\section{Feasible Bids}

The focus of this paper is on the case in which bids are securities. Bidders compete for the project by offering the seller a share of the final payoff. That is, the bids are in terms of derivative securities, in which the underlying asset is the future payoff of the project $Z_{i}$. Bids can be described as function $S(z)$, indicating the payment to the seller when the project has final payoff $z$.

We make the following assumptions regarding the set of feasible bids: ${ }^{6}$

\footnotetext{
${ }^{3}$ We use 'increasing' in the strict sense and explicitly note weak rankings. Similarly when we use 'higher' or 'lower'.

${ }^{4}$ This is equivalent to the log-supermodularity of $h$, which can be written as $\frac{\partial^{2}}{\partial z \partial v} \log h(z \mid v)>0$ assuming differentiability.

${ }^{5}$ More generally, what is required for the SMLRP is that $\log (\theta)$ have a $\log$-concave density function.

${ }^{6}$ These assumptions are typical of the security design literature (e.g. DeMarzo and Duffie (1999), Hart and Moore (1995), and Nachman and Noe (1994)), making it easier to compare our results to the prior literature.
} 
DEFINITION. A feasible security bid is described by a function $S(z)$, such that $S$ is weakly increasing, $z-S(z)$ is weakly increasing, and $0 \leq S(z) \leq z$.

The set of feasible securities encompasses standard designs used in practice. However, it is not completely general, and we discuss and motivate the restrictions below.

First, $S(z) \leq z$ can be viewed as a liquidity or limited liability constraint for the bidder; only the underlying asset can be used to pay the seller. We assume, for now, that bidders do not have access to cash (or other liquid assets) that they can pledge as payment; they can only transfer property rights in the project. ${ }^{7}$ We make this assumption in order to focus first on pure security bids and simplify the exposition; we will generalize the setting to allow for cash payments in Section 5.

Similarly, $S(z) \geq 0$ corresponds to a liquidity or limited liability constraint for the seller; the seller cannot commit to pay the bidder except through a share of the project payoff. For example, the seller may not have the financial resources to do so, which may in fact be the motivation for selling off the project. Because the seller cannot reimburse the bidder for the upfront investment, this assumption rules out a solution a-la Cremer (1987). We take this constraint as given for now, but we show in Section 5 that this constraint can follow from an assumption that the bidder's investment $X$ is not verifiable.

Finally, we require both the seller's and the bidder's payment to be weakly increasing in the payoff of the project. Monotonicity is a standard feature of almost all securities used in practice, and so is a natural constraint to consider. ${ }^{8}$ Most importantly, without monotonicity for the bidders, equilibria would not be efficient, and without monotonicity for the seller, the seller would have incentives to choose other than the highest bid.

Together, these requirements are equivalent to $S(0)=0, S$ is continuous, and $S^{\prime}(z) \in[0,1]$ almost everywhere. Thus, we admit standard sets of securities, including

1. Equity: The seller receives some fraction $\alpha \in[0,1]$ of the payoff: $S(z)=\alpha z$.

2. Debt: The seller is promised a face value $d \geq 0$, secured by the project: $S(z)=$ $\min (z, d)$.

3. Convertible Debt: The seller is promised a face value $d \geq 0$, secured by the project, or a fraction $\alpha \in[0,1]$ of the payoff: $S(z)=\max (\alpha z, \min (z, d))$. (This is equivalent to a debt plus royalty rate contract.)

4. Levered Equity: The seller receives a fraction $\alpha \in[0,1]$ of the payoff, after debt with face value $d \geq 0$ is paid: $S(z)=\alpha \max (z-d, 0)$. (This is equivalent to a royalty agreement in which the bidder recoups some costs upfront.)

\footnotetext{
${ }^{7}$ We assume the bidders can invest $X$ in the project, but $X$ might correspond to an illiquid asset, such as human capital.

${ }^{8}$ A standard motivation for this constraint in the security design literature is that, if it did not hold, parties would have an incentive to "sabotage" the project and destroy output. (Alternatively, if one party could both sabotage the project and artificially inflate the cash flows, a similar constraint would apply. For example, if $S\left(z_{0}\right)>S\left(z_{1}\right)$ for $z_{0}<z_{1}$, the bidder may attempt to inflate the cash flows from $z_{0}$ to $z_{1}$ via a shortterm loan to get payoff $z_{0}-S\left(z_{1}\right)$.) Whether it is reasonable that revenues could be distorted in this way depends on the context. We do not try to defend this assumption here; but point out that it is a standard one, includes typical securities used in practice and guarantees a well-behaved equilibrium.
} 
5. Call Option: The seller receives a call option on the firm with strike price $k$ : $S(z)=\max (z-k, 0)$. Higher bids correspond to lower strike prices. (This equivalent to the bidder retaining a debt claim.)

Given any security $S$, we define

$$
E S(v) \equiv E\left[S\left(Z_{i}\right) \mid V_{i}=v\right]
$$

to denote the excepted payoff of security $S$ conditional on the bidder having value $V_{i}=v$. Thus, the expected payoff to seller if the bid $S$ is accepted from bidder $i$ is $E S\left(V_{i}\right)$. On the other hand, the bidder's expected payoff is given by $V_{i}-E S\left(V_{i}\right)$. Thus, we can interpret $V_{i}$ as the independent, private value for bidder $i$, and $E S\left(V_{i}\right)$ as the payment offered. The key difference from a standard auction, of course, is that the seller does not know the value of the bids, but only the security bid, $S$. The seller must infer the value of this security. Since the security $S$ is monotone, the value of the security is increasing with the signal $V_{i}$ of the bidder, as we show below:

LEMMA 1. The value of the security $E S(v)$ is twice differentiable. For $S \neq 0$, $E S^{\prime}(v)>0$, and for $S \neq Z, E S^{\prime}(v)<1$.

\section{Mergers and Acquisitions}

Thus far we have interpreted the setting as one in which bidders compete for the right to undertake a project. We remark, however, that the model can also be applied to mergers and acquisitions. In this case, the bidders are rival firms, each competing to take over the target company (the seller). We interpret $X$ as the stand-alone value of the acquiring firm plus any acquisition related costs, and $V_{i}$ as the bidder's estimate of the synergy value of the acquisition (i.e. the value of the target once acquired). The bids in this case represent the securities offered to the target shareholders.

\section{Formal Auctions with Ordered Securities}

In many auctions, bidders compete by offering "more" of a certain security. For example, they compete by offering more debt or more equity. We begin our analysis by examining formal auctions in which the seller restricts the bids to elements of a well-ordered set of securities. Bidders compete by offering a higher security.

There are two main reasons why sellers restrict the set of securities that are admissible as bids in the auction. First, it allows them to use standard auction formats - such as first or second-price - to allocate the object and to determine the payments. Without an imposed structure, ranking different securities is very difficult and depends on the beliefs of the seller. There is no objective notion of the "highest" bid.

The second reason a seller may want to restrict the set of securities is that it can enhance revenues. We will demonstrate this result by first (in this section) studying the revenues from auctions with ordered sets of securities and then (in Section 4) comparing this to the revenues from auctions in which the seller cannot commit to a restricted set and bidders can bid using any feasible security.

Before presenting the technical details of the analysis, we consider an example that illustrates our main results. 


\section{Example: Comparison of Revenues Across Securities and Auction Formats}

Two bidders compete for a project that requires an upfront investment of $X=100$. The NPV of the project if run by bidder $i$ is $V_{i}$, where $V_{i}$ is uniform on the interval $[20,110]$. The project is risky, however, with final value $Z_{i}$ which is lognormal with mean $X+V_{i}$ and volatility of $50 \%$.

Total surplus is maximized by allocating the project to the highest type, in this case leading to an expected value of $E\left[\max \left(V_{1}, V_{2}\right)\right]=80$. This is the maximum expected revenue achievable by any auction. On the other hand, using a cash auction, the expected revenue is given by $E\left[\min \left(V_{1}, V_{2}\right)\right]=50$ (which is the same for first and second-price auctions by revenue equivalence). Next, we calculate the revenues for different security designs and auction formats numerically. See Figure 1.

\begin{tabular}{|rcc|}
\hline & \multicolumn{2}{c|}{ Expected Seller Revenues } \\
Security Type & First-price Auction & Second-price Auction \\
\cline { 2 - 3 } & 50.00 & 50.00 \\
Debt & 50.05 & 50.14 \\
Equity & 58.65 & 58.65 \\
Call Option & 74.53 & 74.49 \\
\hline
\end{tabular}

Figure 1: Expected Revenues for Different Security Designs and Auction Formats

Several observations can be made, which coincide with our main results of this section:

1. Fixing the auction format (first or second-price), revenues increase moving from debt to equity to call options. In section 3.2 we will define a notion of "steepness" for securities and show that steeper securities lead to higher revenues, and that all security designs yield higher revenues than cash auctions.

2. The auction format is irrelevant for a cash auction and for an equity auction. While the format does make a difference for debt and call options, the rankings are reversed. In section 3.3 we will generalize these observations and show precisely when revenue equivalence will hold or fail. Overall, though, the impact of the auction format on revenues is minor compared to the security design.

3. Among the mechanisms examined the first-price auction with debt yields the lowest expected revenues while the first-price auction with call options yields the highest expected revenues. In section 3.4 we shall see that these are the worst and best possible mechanisms in a broad class of security-bid auctions, and that all security-bid auctions dominate cash auctions.

\subsection{Securities, Auctions and Mechanisms}

The first step in our analysis is to formalize the notion of an ordered set of securities. An ordered collection of securities can be defined by a function $S(s, z)$, where $s \in\left[s_{0}, s_{1}\right]$ is the "index" of the security, and $S(s, \cdot)$ is a feasible security. That is, $S(s, z)$ is the payment of security $s$ when the output of the project has value $z$. As before we define $\operatorname{ES}(s, v) \equiv$ $E\left[S\left(s, Z_{i}\right) \mid V_{i}=v\right]$.

For the collection of securities to be ordered, we require that its value, for any type, is increasing in $s$. Then, a bid of $s$ dominates a bid of $s^{\prime}$ if $s>s^{\prime}$. We would also like to 
allow for a sufficient range of bids so that for the lowest bid, every bidder earns a nonnegative profit, while for the highest bid, no bidder earns a positive profit. This leads to the following formal requirements for an ordered set of securities:

DEFinition. The function $S(s, z)$ for $s \in\left[s_{0}, s_{1}\right]$ defines an ordered set of securities if:

1. $S(s, \cdot)$ is a feasible security.

2. For all $v, E S_{1}(s, v)>0$.

3. $E S\left(s_{0}, v_{L}\right) \leq v_{L}$ and $E S\left(s_{1}, v_{H}\right) \geq v_{H}$.

Examples of ordered sets include the sets of (levered) equity and (convertible) debt, indexed by the equity share or debt amount, and call options, indexed by the strike price.

Given an ordered set of securities, it is straightforward to generalize the standard definitions of a first and second-price auction to our setting:

FIRST-PRICE AUCTION: Each agent submits a security. The bidder who submitted the highest security (highest $s$ ) wins and pays according to his security.

SECOND-PRICE AUCTION: Each agent submits a security. The bidder who submitted the highest security (highest $s$ ) wins and pays according to the secondhighest security (second-highest $s$ ). ${ }^{9}$

Next, we characterize the equilibria for both types of auction formats. We are interested in the case for which these equilibria are efficient; that is, the case for which the highest value bidder wins the auction. For second-price auctions this is straightforward; the standard characterization of the second-price auction with private values generalizes to:

LEMmA 2. The unique equilibrium in weakly undominated strategies in the second-price auction is for a bidder $i$ who has value $V_{i}=v$ to submit security $s(v)$ such that $E S(s(v), v)=v$. The equilibrium strategy $s(v)$ is increasing.

The above lemma implies that similar to a standard second-price auction, each bidder submits bids according to his true value. We now turn our attention to the first-price auction. Incentive compatibility in the first-price auction implies that no bidder gains by mimicking another type, so that $s(v)$ satisfies

$$
U(v) \equiv \max _{\hat{v}} F^{n-1}(\hat{v})(v-E S(s(\hat{v}), v))=F^{n-1}(v)(v-E S(s(v), v))
$$

where $U(v)$ is the expected payoff of type $v$. The first-order condition of (2) then leads to a differential equation for $s$. However, an additional assumption is required to guarantee the second-order conditions hold:

Assumption C. For all $(s, v)$ such that the bidder earns a positive expected profit, i.e. $v-E S(s, v)>0$, the profit function is log-supermodular:

$$
\frac{\partial^{2}}{\partial v \partial s} \log [v-E S(s, v)]>0 \text {. }
$$

\footnotetext{
${ }^{9}$ Note that with private values, the second-price auction is equivalent to an English auction.
} 
With this assumption we have the following generalization of the standard characterization of the first-price auction to our setting:

LEMMA 3. There exists a unique symmetric equilibrium for the first-price auction. It is increasing, differentiable, and it is the unique solution to the following differential equation:

$$
s^{\prime}(v)=\frac{(n-1) f(v)}{F(v)} \times \frac{[v-E S(s(v), v)]}{E S_{1}(s(v), v)}
$$

together with the boundary condition $\operatorname{ES}\left(s\left(v_{L}\right), v_{L}\right)=v_{L}$.

Thus, given Assumption $\mathrm{C}$, Lemma 3 characterizes the first-price auction and shows that it is efficient. Of course, the question remains regarding how restrictive is Assumption C. ${ }^{10}$ It is a joint restriction on the set of securities and the conditional distribution of $Z$. It can be shown to hold generally in the lognormal setting (1) in the case of debt, equity, and levered equity securities with $d \leq X$. It can be established numerically for other types of securities, such as call options, under suitable parameter restrictions - for example, it holds in the numerical example computed earlier. Throughout our analysis, we assume that it holds for all sets of securities under consideration.

The first and second-price auctions are two standard auction mechanisms. They share the features that the highest bid wins, and only the winner pays. The first property is necessary for efficiency, and the second is natural in our setting, since only the winner can use the assets of the project to collateralize the payment. One can construct many other auction mechanisms, however, that share these properties. For example, one can consider third-price auctions, or auctions where the winner pays an average of the bids, etc. Below we define a broad class of mechanisms that will encompass these examples:

Definition. A General Symmetric Mechanism (GSM) is a symmetric incentive compatible mechanism in which the highest type wins, and pays a security chosen at random from a given set $\boldsymbol{S}$. The randomization can depend on the realization of types, but not on the identity of the bidders (so as to be symmetric).

The first-price auction fits this description, with no randomization (the security is a function of your type). In the second-price auction, the security you pay depends upon the realization of the second-highest type. GSMs also allow for more complicated payment schemes that depend on all of the bids.

It will be useful in what follows to derive a basic characterization of the incentive compatibility condition for a GSM. We show that any GSM can be converted into an equivalent mechanism in which the winner pays a security that depends only on his reported type without further randomization.

\footnotetext{
${ }^{10}$ Assumption $\mathrm{C}$ is the same condition imposed on utility functions in the auction literature; e.g., Maskin and Riley (1984) use it to show existence and uniqueness of equilibria with risk averse bidders. The fact that symmetry and Assumption $\mathrm{C}$ are needed underscores the fact that the efficiency of allocations is more fragile in first-price auctions than in second-price auctions.
} 
LEMMA 4. Incentive compatibility in a GSM implies the existence of securities $\hat{S}_{v}$ in the convex hull of $\boldsymbol{S}$ such that ${ }^{11}$

$$
v \in \arg \max _{v^{\prime}} F^{n-1}\left(v^{\prime}\right)\left(v-E \hat{S}_{v^{\prime}}(v)\right) .
$$

Thus, it is equivalent to a GSM in which the winner pays the non-random security $\hat{S}_{v}$.

This observation will allow us to compare revenues across mechanisms by studying the relationship between the set of securities $\boldsymbol{S}$ and its convex hull.

\subsection{Ranking Security Designs}

Recall from Figure 1 that the seller's revenues varied greatly with the security design. As we will show, the revenues of different designs depend upon the "steepness" of the securities. To do so, we need to formalize the notion of steepness of a set of securities. A simple comparison of the slopes of the securities is inadequate: comparing debt and equity, debt has higher slope for low cash flows and lower slope for high cash flows. Rather, our notion of steepness is defined by how securities cross each other. Intuitively, one security is steeper than another if it crosses that security from below. Thus, we introduce the following definition:

DEFINITION. Security $S_{1}$ strictly crosses security $S_{2}$ from below if $E S_{1}\left(v^{*}\right)=$ $E S_{2}\left(v^{*}\right)$ implies $E S_{1}{ }^{\prime}\left(v^{*}\right)>E S_{2}{ }^{\prime}\left(v^{*}\right)$. An ordered set of securities $S_{1}$ is steeper than an ordered set $\boldsymbol{S}_{2}$ if for all $S_{1} \in \boldsymbol{S}_{\mathbf{1}}$ and $S_{2} \in \boldsymbol{S}_{2}, S_{1}$ strictly crosses $S_{2}$ from below.

The following useful lemma shows that steepness is naturally related to the shape of the underlying securities - if the payoffs of the securities cross from below, then their expected payoffs strictly cross:

LEMMA 5. (Single Crossing) A sufficient condition for $S_{1}$ to strictly cross $S_{2}$ from below is that $S_{1} \neq S_{2}$, and there exists $z^{*}$ such that $S_{1}(z) \leq S_{2}(z)$ for $z<z^{*}$ and $S_{1}(z) \geq S_{2}(z)$ for $z>z^{*}$.

Comparing standard securities, note that a call option is steeper than equity, which in turn is steeper than debt. See Figure 2.

\footnotetext{
${ }^{11}$ A security $S$ is in the convex hull of $S$ if there exists $\pi_{k} \geq 0$ and $S_{k} \in S$ such that $\sum_{k} \pi_{k}=1$ and for all z, $S(z)=\sum_{k} \pi_{k} S_{k}(z)$.
} 


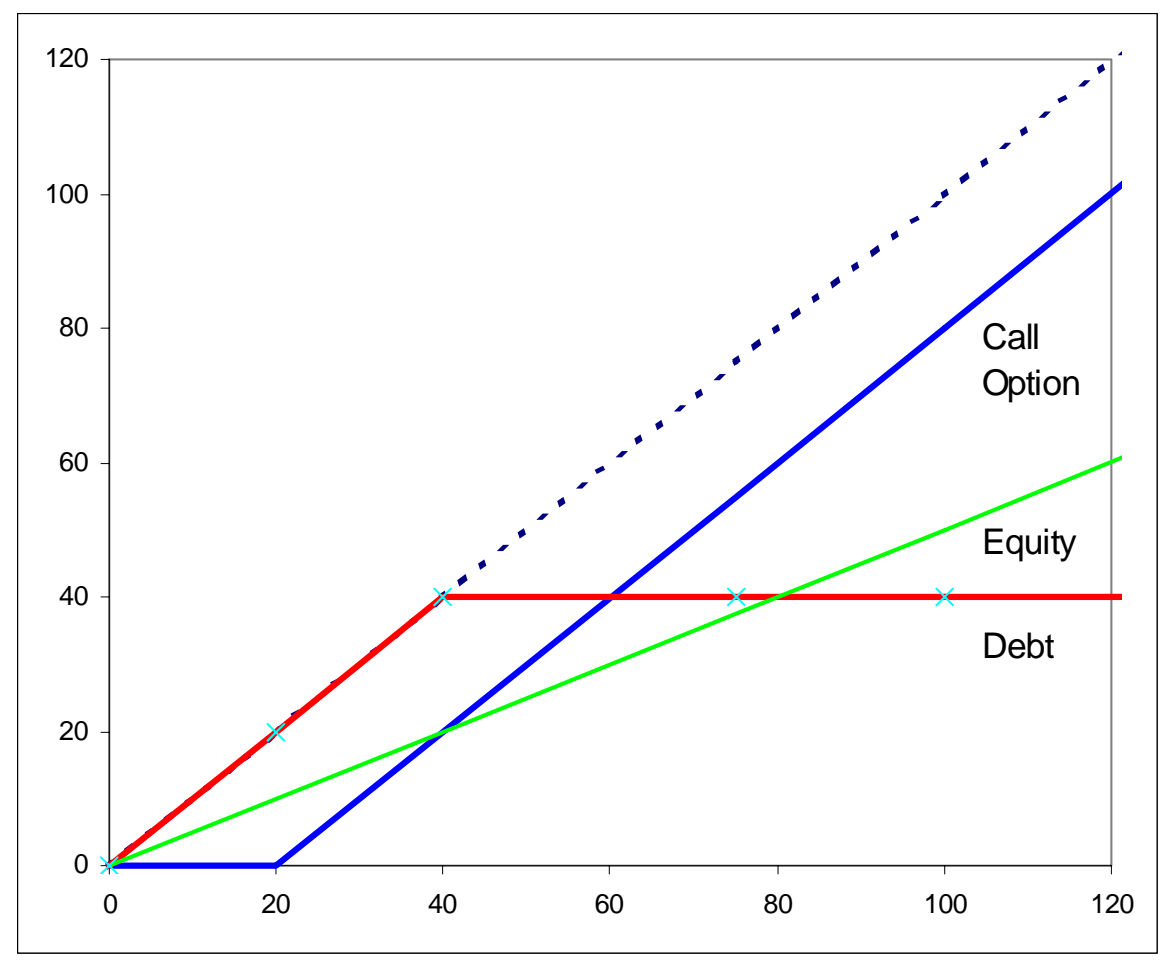

Figure 2: Payoff Diagrams for Call Options, Equity and Debt

Why is steepness related to auction revenues? Consider a second-price auction, where the winning bidder with type $V^{1}$ pays the security bid by the second highest type $V^{2}$. That is, the winner pays $E S\left(s\left(V^{2}\right), V^{1}\right)$. Since bidders bid their reservation value in a secondprice auction, $E S\left(s\left(V^{2}\right), V^{2}\right)=V^{2}$. Hence, the security design impacts revenues only through the difference,

$$
E S\left(s\left(V^{2}\right), V^{1}\right)-E S\left(s\left(V^{2}\right), V^{2}\right)
$$

which is just the sensitivity of the security to the true type. By definition steeper securities are more sensitive, and so lead to higher revenues.

More generally, steepness enhances competition between bidders since even with the same bid, a higher type will pay more. This is the essence of the "Linkage Principle," first used by Milgrom and Weber (1982) to rank auction formats for cash auctions when types are affiliated. ${ }^{12}$ Applying the envelope theorem to the incentive condition (2) for a first-price auction, we get

$$
U^{\prime}(v)=F^{n-1}(v)\left(1-E S_{2}(s(v), v)\right) .
$$

Therefore, bidders' payoffs are lower the higher is $\operatorname{ES}_{2}(s(v), v)$; i.e., the steeper the security. This leads to the following main result:

\footnotetext{
${ }^{12}$ See also Krishna (2002) for a nice summary and discussion. Typically, the linkage principle is used to compare formats when bidders' signals are affiliated. Interestingly, the same argument can be applied to rank security auctions when types are independent. In security-bid auctions, unlike cash auctions, even with independent types the expected payment of the winner depends on his true type, as pointed out by Riley (1988) in the context of royalty rates.
} 
Proposition I. Suppose the ordered set of securities $\boldsymbol{S}_{\mathbf{1}}$ is steeper than $\boldsymbol{S}_{2}$. Then for either a first or second-price auction, for any realization of types, the seller's revenues are higher using $\boldsymbol{S}_{\mathbf{1}}$ than using $\boldsymbol{S}_{2}$.

As a result, flat securities, like debt, lead to low expected revenues, and steep securities, like call options, lead to high expected revenues. In fact, since debt and call options are the flattest ${ }^{13}$ and steepest possible securities, they represent the worst and best designs for the seller. We can also extend the logic of Proposition I to cash auctions, as a cash bid is flatter than any security. Thus, we have the following:

COROLlaRY. For a first or second-price auction, standard debt yields the lowest possible revenues, and call options yield the highest possible revenues, of any security bid auction. All security-bid auctions yield higher revenues than a cash auction.

Note that in all cases, these rankings are for any realization of types, and hence are stronger than the usual comparison based on an expectation over types.

\subsection{Ranking Auction Formats}

In our setting of symmetric independent private values and risk neutrality, a well-known and important result for cash auctions is the Revenue Equivalence Principle. It implies that the choice of the auction format is irrelevant when the ultimate allocation is efficient. ${ }^{14}$ We now turn to examining the revenue consequences of the choice of auction format in a security-bid auction. As we have seen from the numerical example of Figure 1 , revenue equivalence seems to hold for some security designs but not for others. To develop some further intuition, we begin with two simple examples.

\section{Example: Equity Auctions and Revenue Equivalence}

There are two bidders with independent types $V_{i}$ distributed uniformly on $[0,1]$. Upfront investment is $X=1$. The distribution of $Z_{i}$ has full support with mean $X+V_{i}$.

Consider a second-price equity auction. As we know, it is a dominant strategy to bid the reservation value: $\alpha^{\mathrm{SPA}}(v)=\frac{v}{v+1}$, which is increasing in $v$. In a first-price auction it is an equilibrium strategy for agents to bid $\alpha^{F P A}(v)=1-\frac{\ln (1+v)}{v}$, which is also increasing. ${ }^{15}$

Now observe that both auctions yield equal payoffs to the auctioneer, as in both auction formats the highest type wins and the average losing bid in a second-price auction equals the highest bid in the first-price auction:

\footnotetext{
${ }^{13}$ By flattest, we mean that all other sets of securities are steeper.

${ }^{14}$ Vickery (1961), Myerson (1981), Riley and Samuelson (1981).

${ }^{15}$ To verify that this is indeed an equilibrium consider the payoff of a type $v$ who pretends to be $v$ ':$$
v^{\prime}\left[\frac{\ln \left(1+v^{\prime}\right)}{v^{\prime}}(1+v)-1\right]=(1+v) \ln \left(1+v^{\prime}\right)-v^{\prime}
$$

and note that it is maximized by setting $v^{\prime}=v$.
} 


$$
E\left[\frac{V_{2}}{V_{2}+1} \mid V_{2} \leq v_{1}\right]=1-\frac{\ln \left(1+v_{1}\right)}{v_{1}}
$$

From this example one may be tempted to conclude that revenue equivalence across auction formats holds for all security-bid auctions. Interestingly, as the next example shows this is not the case for all securities. ${ }^{16}$

\section{Example: Second-Price Auctions Yield Higher Revenues for Debt}

Consider a debt auction. There are two bidders, types $V_{i}$ are independent and uniform on on $[0,1], X=0$, and the distribution of $Z_{i}$ given $V_{i}$ is uniform on $\left[0,2 V_{i}\right] .^{17}$ If a bidder wins and pays according to a debt bid with face value $b$ the payoff to the seller is $\min (b, z)$ which for a type $v$ yields on average:

$$
E\left[Z_{i}-\min \left(b, Z_{i}\right) \mid V_{i}=v\right]=\frac{1}{2 v} \int_{b}^{2 v}(z-b) d z=\frac{(2 v-b)^{2}}{4 v} .
$$

In a second-price auction it is an equilibrium strategy for agents to bid their reservation values: $b^{S P A}(v)=2 v$. In a first-price auction it is an equilibrium strategy to bid $b^{F P A}(v)=\frac{2}{3} v \cdot 18$

Suppose, without loss of generality, that bidder 1 wins the auction. In a first-price auction, his payoff is

$$
\frac{\left(2 v_{1}-b^{F P A}\left(v_{1}\right)\right)^{2}}{4 v_{1}}=\frac{\left(2 v_{1}-2 v_{1} / 3\right)^{2}}{4 v_{1}}=\frac{4}{9} v_{1},
$$

while in a second-price auction, his payoff is

$$
E\left[\frac{\left(2 v_{1}-b^{S P A}\left(V_{2}\right)\right)^{2}}{4 v_{1}} \mid V_{2} \leq v_{1}\right]=E\left[\frac{\left(2 v_{1}-2 V_{2}\right)^{2}}{4 v_{1}} \mid V_{2} \leq v_{1}\right]=\frac{1}{v_{1}} \int_{0}^{v_{1}} \frac{\left(v_{1}-v_{2}\right)^{2}}{v_{1}} d v_{2}=\frac{v_{1}}{3}
$$

We conclude that bidders' welfare is higher in the first-price auction and, since in both auction formats the highest type wins, revenues are higher in the second-price auction. Thus, revenue equivalence fails.

To gain some insight into why revenue equivalence fails, note that in the second-price auction, the winner pays a random security (determined by the second highest bid). This is equivalent to paying a convex combination of securities. Now, a convex combination

\footnotetext{
${ }^{16}$ We thank a referee for this example.

${ }^{17}$ While this example violates some of our technical assumptions ( $X>0$ and $Z$ has full support), it provides a simple closed form solution (and also suggests that our results are somewhat more general).

${ }^{18}$ To verify that this is an equilibrium note from (4) that the payoff of a type $v$ who pretends to be $v^{\prime}$ is$$
v^{\prime} \frac{\left(2 v-2 v^{\prime} / 3\right)^{2}}{4 v}
$$

which is maximized for $v^{\prime}=v$.
} 
of debt securities is not a debt security. ${ }^{19}$ Specifically, in the second-price debt auction, the winner's payment is equivalent to paying the "expected" security

$$
S_{v_{1}}(z)=E\left[\min \left(z, 2 V_{2}\right) \mid V_{2} \leq v_{1}\right]=z-\frac{z^{2}}{4 v_{1}}
$$

in a first price auction. ${ }^{20}$ This security is not a debt security, and therefore is steeper than debt. As a result of this steepness, the seller's revenues are enhanced. On the other hand, in the case of equity, a convex combination of securities is also an equity security. Thus there is no change in steepness, and so no change in revenues.

\section{Sub and Super-Convex Sets of Securities}

The previous examples suggest that the revenue differences across auction formats will stem from the differences in steepness between the set of securities and its convex hull. This motivates the following formal classification:

Definition. An ordered set of securities $S=\left\{S(s, \cdot): s \in\left[s_{0}, s_{1}\right]\right\}$ is superconvex if it is steeper than any non-trivial convex combination of the securities in $\boldsymbol{S}$. It is sub-convex if any non-trivial convex combination of the securities in $\boldsymbol{S}$ is steeper than $\boldsymbol{S}$. $^{21}$

Not every set falls into one of the above categories. Still, there are some important examples of sub- and super-convex sets:

LEMMA 6. The set of standard debt contracts is sub-convex. The set of convertible debt contracts indexed by the equity share $\alpha$, the set of levered equity contracts indexed by leverage, and call options are super-convex sets.

Based on the above characterization, we can again use the Linkage Principle to rank the expected revenues of first and second-price auctions. Here the proof relies on Lemma 4, which allows us to interpret the second-price format as a first-price mechanism in the convex hull of the set of securities:

Proposition II. If the ordered set of securities is sub-convex, then the first-price auction yields lower expected revenues than the second-price auction. If the ordered set of securities is super-convex, the first-price auction yields higher expected revenues than the second-price auction. This revenue comparison also holds conditional on the winner's type, for all but the lowest type.

One subtlety in the proof of Proposition II is that the security paid by the lowest type is the same for both auction formats (and is defined by the zero profit condition). Thus neither format employs a "steeper" security for that type. We get around this problem by slightly perturbing the support of the types for one of the auction formats, comparing revenues, and taking the limit.

\footnotetext{
${ }^{19}$ For example, consider a 50-50 mix of debt with face value 50 and debt with face value 100 . For $z \in$ $(50,100)$, this security has slope $1 / 2$ and so is not a debt security.

${ }^{20}$ In this example the support of $Z_{1}$ is bounded by $2 v_{1}$, so the security is monotone. Note that the bidder's expected payoff with this security is $E\left[Z_{1}-S_{v_{1}}\left(Z_{1}\right) \mid V_{1}=v_{1}\right]=E\left[Z_{1}^{2} / 4 v_{1} \mid V_{1}=v_{1}\right]=v_{1} / 3$, as before.

${ }^{21}$ A non-trivial convex combination puts positive weight on more than one security.
} 
Proposition II reveals that the auction format can impact revenues. However, as we have seen, this revenue impact stems from the difference in steepness between the set of securities and their convex hull. This difference is always less extreme than the difference in steepness that can be obtained by changing the security design directly. In that sense, the design of the securities is much more important than the design of the auction format in determining revenues.

\section{Revenue Equivalence for Convex Sets of Securities}

While revenue equivalence does not hold for general security auctions, it does hold for cash, and holds for equity in our examples. Here we ask whether it can be recovered for some classes of securities - that is, what is special about cash?

From Proposition II, revenue equivalence fails in one direction for a super-convex set, and in the opposite direction for a sub-convex set. Hence, a natural candidate is a set in the middle; i.e., a convex set:

Definition. An ordered set of securities $S$ is convex if it is equal to its convex hull.

In fact, convex sets of securities have a simple characterization - each security is a convex combination of the lowest security $s_{0}$ and the highest security $s_{1} .{ }^{22}$ Thus, each security can be thought of as $s_{0}$ plus some "equity shares" of the security $\left(s_{1}-s_{0}\right)$, and so it can be thought of as a generalization of a standard equity auction. Our main result in this section is that under convexity, the Revenue Equivalence continues to hold.

Proposition III (Revenue Equivalence). Every efficient equilibrium of a general symmetric mechanism (GSM) with securities from an ordered convex set yields the same expected revenues. This equivalence also holds conditional on the winner's type.

Note that this is a stronger statement than equivalence between a first and second-price auction, as it holds for any symmetric mechanism. Also note that the standard envelope argument behind Revenue Equivalence does not extend directly to security auctions. For cash, there is no linkage between the true type and the bidder's expected payment when types are independent, so revenues only depend upon the allocation. ${ }^{23}$ That is not the case with security-bids, as we have seen. However, when the security set is convex, because paying a random security is equivalent to paying the expected security drawn from the same set, the expected linkage across all mechanisms is identical.

Thus, we have shown that the important property needed for the revenue equivalence principle is that the securities be ordered and convex. This is true for cash, but also true more generally for equity-type auctions. Also, because we can construct a first-price equilibrium by computing the expected security in a second-price equilibrium, we can

\footnotetext{
${ }^{22}$ To see why, note that since the set is convex, for each $\lambda$ there exists a mapping $s:[0,1] \rightarrow\left[s_{0}, s_{1}\right]$ such that $S(s(\lambda), z)=(1-\lambda) S\left(s_{0}, z\right)+\lambda S\left(s_{1}, z\right)$. Then $s(0)=s_{0}, s(1)=s_{1}$ and since the set is ordered and $s_{0} \neq s_{1}$, $s(\lambda)$ is increasing. Thus, the result follows if $s(\lambda)$ is continuous. But since $E S(s(\lambda), v)=(1-\lambda) E S\left(s_{0}, v\right)+\lambda$ $E S\left(s_{1}, v\right)$ is continuous, so is $s(\lambda)$ since $E S(s, v)$ is increasing in $s$.

${ }^{23}$ That is, in the case of cash auctions, (3) reduces to $U^{\prime}(v)=F^{n-1}(v)$.
} 
weaken our condition for the existence of an efficient equilibrium in the first-price auction:

Corollary. Even absent Assumption C, given a convex ordered set of securities, there exists an efficient symmetric equilibrium in a first-price auction with the same expected revenues as in a second-price auction.

\subsection{Best and Worst Mechanisms}

We can combine the results of the previous two sections to determine the best and worst security design and format combinations. Note that, since debt is a sub-convex set, from Proposition II the first-price auction is inferior to the second-price auction, and conversely for call options, which are super-convex. The following proposition establishes that a first-price auction with debt and with call options bound the range of outcomes for the seller for a broad class of mechanisms.

Proposition IV. A first-price auction with call options yields the highest expected revenues amongst all general symmetric mechanisms. A first-price auction with standard debt yields the lowest expected revenues amongst all general symmetric mechanisms.

PROOF: The proof follows that of Proposition II, except that instead of the second-price auction we consider a general symmetric mechanism over some subset of the feasible securities. The result follows as a call option contract is steeper and a standard debt contract is flatter than any convex combination of feasible securities (where we use the same trick as in the proof of the Corollary to Proposition I if the sets of securities intersect).

Proposition IV establishes that the design of the security is more important than the specific auction format: the revenue consequences of shifting from debt to call options in a first-price auction exceeds the consequences of any change in the auction mechanism.

We remark that Proposition IV is stated with respect to the particular set of feasible securities we have allowed thus far. It can be extended in the obvious way: for any feasible set, if there is a steepest set of securities which is (super-)convex, then a (firstprice) auction using this set yields the highest possible revenues. Similarly, if there is a flattest set which is (sub-)convex, then a (first-price) auction using this set yields the lowest possible revenues.

For example, if bidders can pay cash, a cash auction is the worst possible auction for the seller. This is because cash, which is insensitive to type, is even flatter than standard debt securities (see Section 5.1 for a further discussion of this case).

Alternatively, the seller may be able to increase revenues by using securities that are even more leveraged than call options. For example, the seller might pay the bidder cash for additional equity. This strategy is related to the result of Cremer (1987). We have assumed so far that the seller does not have the resources to make such a payment. We also show in Section 5 that even if the seller does have the resources, due to moral hazard he will not make such payments if the bidder's investment $X$ is non-verifiable. (Indeed, even call options may be too levered in some settings of moral hazard, as we discuss in our concluding remarks). 


\section{Informal Auctions: The Signaling Game}

In the previous section we considered formal auctions in which bidders are restricted to choose securities from a specific well-ordered set. In reality, there is often no such restriction. That is, the seller is unable to commit to ignore offers that are outside the set. As a result, the seller will consider all bids, choosing the most attractive bid ex-post. In this case, the "security design" is in the hands of the bidders, who can choose to bid using any feasible security.

Without the structure of a well-ordered set, once the bids are submitted there is no obvious notion of a "highest" bid. In this case, the seller faces the task of choosing one of the submitted bids. Since there is no ex-ante commitment by the seller to a decision rule, the seller will choose the winning bid that offers the highest expected payoff. Since the payoff of the security depends on the bidder's type, the seller's choice may depend upon his beliefs regarding the bid each type submits in equilibrium. Thus, this setting has the features of a signaling game that takes the form:

1. Bidders submit simultaneous bids that are feasible securities.

2. The seller chooses the winning bid.

3. The winner pays his bid and runs the project.

We consider a sequential equilibrium of this game. We argue that in the informal auctions bidders will choose the flattest securities possible. That is, they will bid with cash, if it is feasible; otherwise, they will bid with debt. Thus, Proposition IV implies that the seller's expected revenues are the lowest possible from any general auction mechanism.

To gain some insight, consider first a case in which bidders can use cash. We argue that in equilibrium bidders use only cash. The intuition for this result is as follows. Let $S_{v}$ be the security bid by type $v$. When a bidder of type $v$ decides on his bid, he has the option to mimic other types. In particular, he can mimic a type $v^{\prime}=v-d v$ just below him. Such a deviation has two effects. First, it will reduce his probability of winning to that of type $v^{\prime}$. Second, it will lower his expected payment if he wins from $E S_{v}(v)$ to $E S_{v^{\prime}}(v)$. On the margin, these two effects must balance out (otherwise there is a profitable deviation).

But now suppose types just below $v$ use security bids rather than cash. Consider the deviation by type $v$ to a cash bid of amount $b\left(v^{\prime}\right)=E S_{v^{\prime}}\left(v^{\prime}\right)$. Since the seller values this cash bid the same as the bid $S_{v^{\prime}}$ by type $v^{\prime}$, the marginal effect on the probability of winning is the same as if he deviates to $S_{v^{\prime}}$. However, because the expected value of the security is increasing in the true type, the expected payment is $b\left(v^{\prime}\right)=E S_{v^{\prime}}\left(v^{\prime}\right)<E S_{v^{\prime}}(v)$. Thus, if type $v$ is indifferent to a deviation using securities, he will profit from a deviation using cash. As a result, an equilibrium will only involve cash bids.

The second step of the logic above can be applied even when cash bids are not available. When mimicking a lower type, it is cheaper for a higher type to use a security that is less sensitive to the true type - i.e., a flatter security - than that used in the proposed equilibrium. This reasoning suggests an equilibrium will involve the flattest securities available. 
However, there is a difficulty with extending this result when cash is not available. The gain from a deviation depends crucially on the seller's evaluation of the bid. The argument we gave above is simplified by the fact that the value of a cash bid is unambiguous; the seller does not need to rely on his beliefs. But when bidders do not use cash, the value of any off-equilibrium bid depends on the seller's off-equilibrium beliefs. As with general signaling games, there are many equilibria of this game if we do not impose any restrictions on the beliefs of the seller when an "unexpected" bid is observed. $^{24}$ We turn to such restrictions next.

\section{Refining Beliefs - The D1 Criterion}

To rule out equilibria supported with arbitrary off-equilibrium beliefs, the standard refinement in the signaling literature is the notion of strategic stability, introduced by Kohlberg and Mertens (1986). For our purposes, a weaker refinement, known as D1, is sufficient to identify a unique equilibrium. ${ }^{25}$ The D1 refinement (see Cho and Kreps (1987), Cho and Sobel (1990)) is a refinement commonly used in the security design literature. $^{26}$ Intuitively, the D1 refinement criterion requires that if the seller observes an out-of-equilibrium bid, the seller should believe the bid came from the type "most eager" to make the deviation.

In order to define the D1 criterion in our context, we introduce the following notation. First, let $S^{i}$ be the random variable representing the security bid by bidder $i$, which will depend on $V_{i}$. For any feasible security $S$, let $R^{i}(S)$ be the scoring rule assigned by the seller, representing the expected revenues the seller anticipates from that security, given his beliefs. Along the equilibrium path, the seller's beliefs are correct, so that the scoring rule satisfies

$$
R^{i}(S)=E\left[E S\left(V_{i}\right) \mid S^{i}=S\right]
$$

Given the seller's scoring rule, $R^{i}$, it must also be the case in equilibrium that bidders are bidding optimally. That is, conditional on $V_{i}=v, S^{i}$ solves

$$
U^{i}(v)=\max _{S} P^{i}\left(R^{i}(S)\right)(v-E S(v)),
$$

where $P^{i}(r)$ is the probability that $r$ is the highest score. ${ }^{27}$ Thus, $U^{i}(v)$ is the equilibrium expected payoff for bidder $i$ with type $v$.

Suppose the seller observes an out-of-equilibrium bid, so that the score is not determined by (5). Which types would be most likely to gain from such a bid? For each type $v$, we can determine the minimum probability of winning, $B^{i}(S, v)$, that would make bidding $S$ attractive:

\footnotetext{
${ }^{24}$ In our context, if the seller believes all off-equilibrium bids are made by the lowest type, this will minimize the gain from deviating using securities. These beliefs seem unreasonable, however, since many securities would be unprofitable for the lowest type.

${ }^{25}$ Strictly speaking, D1 is defined for discrete type spaces. However, it can be naturally extended to continuous types (see, e.g., Ramey 1996).

${ }^{26}$ See, e.g. Nachman and Noe (1994) and DeMarzo and Duffie (1999).

${ }^{27}$ If there are ties, we require that $P^{i}$ be consistent with some tie-breaking rule.
} 


$$
B^{i}(S, v)=\min \left\{p: p(v-E S(v)) \geq U^{i}(v)\right\} .
$$

Then the D1 criterion requires that the seller believe that a deviation to security $S$ came from the types which would find $S$ attractive for the lowest probability of winning: ${ }^{28}$

$$
R^{i}(S) \in E S\left(\arg \min _{v} B^{i}(S, v)\right) .
$$

Thus, a sequential equilibrium satisfying the D1 criterion for the auction game can be described by scoring rules $R^{i}$ and bidding strategy $S^{i}$ for all $i$ satisfying (5)-(7).

\section{Equilibrium Characterization}

Using the D1 refinement, we can now extend the argument we made for cash deviations to other securities. Suppose type $v$ mimics type $v^{\prime}=v-d v$. The cost of doing so for type $v$ is $E S_{v^{\prime}}(v)$. Now suppose $v$ instead deviates to a security $S$ that is flatter than $S_{v^{\prime}}$ and such that $E S\left(v^{\prime}\right)=E S_{v^{\prime}}\left(v^{\prime}\right)$. Because the security is flatter, it has a lower cost for type $v$, $E S(v)<E S_{v^{\prime}}(v)$. How would the seller respond to the deviation $S$ ?

Because $S$ is flatter than $S_{v^{\prime}}$, it is a more expensive security for types below $v^{\prime}$, and cheaper for types above $v^{\prime}$, than $S_{v^{\prime}}$. Therefore, the types that are "most eager" to deviate to $S$ must be above $v^{\prime}$. By D1, this implies that the seller will evaluate $S$ as at least as valuable as $S_{v^{\prime}}$. Therefore, if type $v$ is indifferent to a deviation to $S_{v^{\prime}}$, he will profit from a deviation to a flatter security $S$. As a result, an equilibrium will involve only the flattest possible securities.

We now proceed with a formal statement of our results. As is standard in the auction setting, we will focus on symmetric equilibria. ${ }^{29}$ We continue to maintain Assumption C for standard debt, so that existence of an efficient equilibrium of the first-price auction is assured. Then we have

Proposition V. Given symmetric strategies, there is a unique equilibrium of the informal auction satisfying D1. This equilibrium is equivalent, in both payoffs and strategies, to the equilibrium of a first-price auction in which players bid with the flattest securities feasible. In particular, if they can bid with cash, they will only use cash; if cash is not feasible, they will bid with standard debt contracts.

Again, we can now combine this result with the result of the previous section to formalize the value of the seller's ability to commit to a restricted set of securities.

Corollary. If the seller can commit to a formal auction with an ordered set of securities other than debt contracts, then expected revenues are higher than without such commitment.

Proof: Follows immediately from Proposition IV and Proposition V.

\footnotetext{
${ }^{28}$ We have economized on notation here. If the set of minimizers is not unique, the score is in the convex hull of $E S(v)$ for $v$ in the set of minimizers.

${ }^{29}$ That is, we restrict attention to equilibria in which the bidders use symmetric strategies and the seller uses the same scoring rule for all players.
} 


\section{Extensions}

Here we consider several extensions to the basic model. First, we consider expanding the space of security bids by relaxing the liquidity constraints. Second, we consider expanding the space of mechanisms by allowing the seller to set reservation bids. Third, we consider changing the information structure by allowing for correlated types and common values.

\subsection{Relaxing the Liquidity Constraints}

We have assumed that both the seller and the bidders are liquidity constrained. We now explore implications of either the seller or bidders having access to cash.

\section{Moral Hazard: Non-Contractible Investment}

Up to now, we have restricted bids to satisfy $S(0) \geq 0$ assuming the seller is liquidity constrained. But if the seller has cash, securities in which the seller reimburses the winner for a portion of the initial investment (and thus have $S(0)<0$ ) are feasible. Importantly, these securities can be steeper than call options and so increase revenues. For example, the seller could auction off the rights to a fraction $\varepsilon$ of the cash flows, and reimburse the winner directly for the investment $(1-\varepsilon) X$. By making $\varepsilon$ arbitrarily small, the seller can extract the entire surplus. While this theoretical mechanism was proposed by Cremer (1987), it is not observed in practice. A likely reason is moral hazard: if the winner's investment is not fully contractible, and if the winner receives only a small fraction of future revenues, then he may under-invest. ${ }^{30}$

For example, suppose that after the auction the winning bidder $i$ can choose whether to invest $X$. If $X$ is invested, the payoff of the project is $Z_{i}$ as before, and his payment to the seller is $S\left(Z_{i}\right)$. If $X$ is not invested, the payoff is 0 , and his payment to the seller is $S(0)$. If $S(0) \geq 0$, the bidder's payoff is non-positive without investment, and so the option not to invest is irrelevant. But suppose a bid with $S(0)<0$ is accepted with positive probability. Then every bidder, including the lowest type, can earn positive profits by making such a bid and not investing. Yet if bidders do not invest and $S(0)<0$, the seller loses money. As a result, the seller would choose not to accept such securities, as shown below:

Proposition VI. Suppose that the seller is not liquidity constrained and the investment $X$ is not contractible. Then,

1. In a first and second-price formal auction (with an ordered set of securities):

a. If a security without reimbursement is allowed, then with probability 1 the winning bid satisfies $S(0) \geq 0$. That is, competition between bidders rules out reimbursement.

\footnotetext{
${ }^{30}$ A real example of the importance of moral hazard is provided by several oil lease auctions run by the U.S. Department of the Interior in which the bidders bid high royalty rates (see Binmore and Klemperer (2002)). As a result, though development was economically efficient, many of the oil fields were left undeveloped because bidders did not capture enough of the revenues to warrant their private investment. In the end, the government was left with almost no revenues.
} 
b. If all securities involve reimbursement, then all bidders bid the highest allowed security and do not invest, leading to negative revenues for the seller.

2. Any mechanism in which bids with $S(0)<0$ win with positive probability cannot be efficient.

3. In an informal auction, securities with $S(0)<0$ are used with probability 0 .

Thus, when $X$ is not contractible, even if the seller has cash we can rule out reimbursement from the seller - it would either not occur in equilibrium or not be in the seller's best interest.

\section{Partial Cash Bids}

Suppose bidders have cash equal to $B$, where $B$ is known and common to all bidders. ${ }^{31}$ Cash relaxes the limited liability restriction for bidders so that the flattest securities are now debt claims on the total assets of the bidder (cash + project), defined by

$$
S^{D}(d, z)=\min (d, B+z)=\min (d, B)+\min \left((d-B)^{+}, z\right) .
$$

As the decomposition above reveals, we can think of this security as an immediate cash payment (up to $B$ ), plus a standard debt claim on the project (for amounts above $B$ ). Because these securities become flatter as $B$ increases, the seller's expected revenues decrease with $B$. A pure cash auction, yielding the lowest possible revenues, is possible for a second-price auction if $B$ exceeds $v_{H}$, and for a first-price auction if $B$ exceeds the expected maximum type for $n-1$ bidders (which is less than $v_{H}$ ). Thus a first-price auction yields lower revenues for the seller as long as $B<v_{H}$. These results are consistent with Board (2002), who considers debt auctions and shows that they yield higher revenues than cash auctions, with the smallest effect for first-price auctions.

\subsection{Reservation Prices}

In this section we discuss briefly how reservation prices can be incorporated into our analysis. Commitment to a reservation price can improve the seller's revenues, and even absent commitment, a reservation price may be relevant if selling the project entails an opportunity cost.

In the case of formal auctions, we assumed earlier that the lowest security, $s_{0}$, was such that all types earn non-negative profits; that is, $E S\left(s_{0}, v_{L}\right) \leq v_{L}$. A reservation price is equivalent to assuming that $s_{0}$ restricts that set of types that can profitably participate. In particular, if we choose $s_{0}$ so that

$$
E S\left(s_{0}, v_{r}\right)=v_{r}
$$

for some type $v_{r} \in\left[v_{L}, v_{H}\right]$, then $v_{r}$ is the reservation price ${ }^{32}$, and types below $v_{r}$ will not be allocated the project.

\footnotetext{
${ }^{31}$ Che and Gale (2000), Rhodes-Kropf and Viswanathan (2002), and Zheng (2001) consider models where the cash amount is heterogeneous and privately known.

${ }^{32}$ We refer to this as a "price" since it is the minimum amount the seller will accept in order to sell the object.
} 
All of our results regarding formal auctions generalize to this case. In particular, holding fixed the reservation price, the seller's revenues are higher using steeper securities. In addition, first-price auctions are superior for super-convex (sets of) securities, secondprice auctions are superior for sub-convex securities, and revenue equivalence holds for convex ordered securities. The proof of these results follows exactly as the proofs in Section 3: we apply the linkage principle to compare $U^{\prime}(v)$ across settings, but now use the boundary condition $U\left(v_{r}\right)=0$ rather than $U\left(v_{L}\right)=0$.

A similar generalization applies to informal auctions. There, since there is no commitment, it is natural to interpret $v_{r}$ as the outside opportunity for the seller. Thus, the seller will not sell unless he believes the best security is worth more than $v_{r}$. Consider the standard debt security $S_{r}^{d}$ defined by $E S_{r}^{d}\left(v_{r}\right)=v_{r}$. Types below $v_{r}$ would lose money submitting this security. Thus, in a D1 equilibrium, the seller must believe the bidder submitting $S_{r}^{d}$ is at least type $v_{r}$, and this bid would be accepted. The remainder of the proof can be extended to show that the unique D1 equilibrium is a first-price standard debt auction with reservation price $v_{r}$, which has the lowest possible revenues for any auction mechanism with this reservation price.

\subsection{Affiliated Private and Common Values}

Our model thus far is based on the classic independent private value framework. We discuss here how our results generalize when values are affiliated (see Milgrom and Weber, 1982) and may have common, as well as private, components. ${ }^{33}$ Formally we assume that:

Assumption D. The private signals $V=\left(V_{1}, \ldots, V_{n}\right)$ and payoffs $Z=\left(Z_{1}, \ldots, Z_{n}\right)$ satisfy the following properties:

1. The private signals $V_{i}$ are affiliated and distributed symmetrically with full support $\left[v_{L}, v_{H}\right]$.

2. Conditional on $V=v$, the payoff $Z_{i}$ has density $h\left(z \mid v_{i}, v_{-i}\right)$ with full support [0, $\infty)$. The distribution is symmetric in the last $n-1$ arguments.

3. $(Z, V)$ are strictly affiliated.

First we consider formal auctions with a fixed auction format. Under appropriate conditions there exists a unique symmetric increasing equilibrium for both the first and the second-price auction. ${ }^{34}$ Given an efficient equilibrium, we can generalize our result regarding the impact of the security design on the resulting revenues: ${ }^{35}$

\footnotetext{
${ }^{33}$ Affiliation (essentially, the log-supermodularity of the joint density function) implies that "good news" about one of the variables (learning it lies in a higher interval), raises the expectation of any monotone function of the variables. With two random variables, it is equivalent to the MLRP.

${ }^{34}$ For a second-price auction we do not need extra conditions. For a first-price auction, we again need logsupermodularity of the winner's profit, which becomes more complicated in this case.

${ }^{35}$ See appendix for proofs.
} 
- Given a symmetric increasing equilibrium, then fixing the mechanism (first or second-price), steeper sets of securities yield higher revenues for the seller. ${ }^{36}$

The intuition for this result is the same as before - steeper securities increase the effective competition between bidders since they are more costly for higher types.

What about the comparison of auction formats? Here it is useful to consider first the case of affiliated private values (i.e., $h\left(z \mid v_{i}, v_{-i}\right)$ does not depend on $\left.v_{-i}\right)$. In this setting, revenue equivalence fails even for cash auctions, as shown by Milgrom and Weber (1982). In our setting,

- With affiliated private values, for both convex and sub-convex sets of securities, second-price auctions generate higher expected revenues than first-price auctions.

This result again follows from the linkage principle, since the second-highest bid is affiliated with, or "linked" to, the winner's value. This linkage creates an advantage for the second-price auction.

On the other hand, if there is a common value component to the asset, this can have an opposing effect regarding the optimal auction format, and create and advantage for a first-price auction. We show this below for a case of independent signals and common value:

- Suppose $V_{i}$ are independent, and $E\left[Z_{i} \mid V\right]=\sum_{j} V_{j} \cdot{ }^{37}$ Then for an equity auction, the first-price auction generates higher expected revenues than a secondprice auction.

The intuition for this result is that, since the equity-share is increasing with the bidder's type, and therefore correlated with the asset's value, to generate the same expected revenues the expected equity-share in the second-price auction is lower than in the firstprice auction. But the lower average equity share reduces the linkage to the winner's own type, reducing revenues in the second-price auction.

Finally, consider the setting of an informal auction. With affiliated private values, our conclusions regarding the informal auction hold - high types prefer to use flat securities to separate from lower types:

- In the unique D1 equilibrium, bidders use the flattest possible securities leading to the lowest revenues for the seller. ${ }^{38}$

With common values the signaling game becomes much more complex. Now, after observing the bids, the seller is potentially more informed than the bidder. Thus the bidder faces an adverse selection problem. This adverse selection is mitigated by making the seller's payoff sensitive to revenues, potentially leading bidders to bid using steeper securities. We leave the analysis of this case for future research.

\footnotetext{
${ }^{36}$ In this case, the notion of steepness is that given in Lemma 5, which, combined with affiliation, will imply that securities strictly cross in terms of their expected costs.

${ }^{37}$ This is the so-called "Wallet Game"; see Bulow and Klemperer (2002).

${ }^{38}$ The proof is the same as Proposition V with a minor modification to step 3. Intuitively, affiliation provides the seller with information about the bidder's type after observing other bids, but this plays no role in a separating equilibrium.
} 


\section{Conclusion}

We have examined an aspect of bidding relatively ignored in auction theory - the fact that bidders' payments often depend on the realization of future cash flows. This embeds a security design problem within the auction setting. First we analyzed formal auctions in which the seller chooses the security design and restricts bidders to bid only using securities in an ordered set. This enables a simple ranking of the securities and the use of standard auction formats. We showed conditions for which Revenue Equivalence holds, and determine the optimal and worst format and security design combinations. In particular, we showed that revenues are increasing in the steepness of the securities, and demonstrated that the first-price debt auction yields the lowest revenues, whereas a firstprice auction with call options yields the highest revenues, across a broad class of possible mechanisms.

Next we considered informal auctions in which the seller does not restrict the set of securities or the mechanism ex ante, but chooses the most attractive bid ex post. In this case, security design is in the hands of the bidders. We show that this yields the lowest possible expected revenues for the seller, and is equivalent to a first-price auction using the flattest feasible securities, such as debt or cash. Thus there are strong incentives for the seller to be actively involved in the auction design and select the securities that can be used.

Finally, we generalized our results to include relaxed liquidity constraints (incorporating aspects of moral hazard), partial cash bids, reservation prices, and affiliated and common values. All of our main insights and results are robust to these features.

There are a number of natural extensions to our framework. For example, the role of the security design often extends beyond the auction to determine the winner's and seller's incentives ex-post. While we discuss a simple moral hazard setting in Section 5.1, more general settings can be considered. Some of these can be modeled as further restrictions on the set of feasible securities. For example, consider the case in which the winner has the opportunity to divert cash flows from the project, with each dollar diverted generating a private payoff of $\delta<1 .{ }^{39}$ In this case, by the usual revelation principle argument, we can restrict attention to securities that do not induce diversion; i.e., such that $1-S^{\prime}(z) \geq \delta$. Because this limits the steepness of the security, it lowers the revenues the seller can achieve using the optimal formal auction. On the other hand, it also rules out debt. So if bidders are cash constrained, the flattest possible securities have the form $S(d, z)=\min (d$, $(1-\delta) z)$. Because these securities are not as flat as standard debt, the revenues of the seller are in fact enhanced by this restriction. ${ }^{40}$

More generally, our analysis provides clear intuition for the way in which moral hazard concerns will interact with competition and revenues in the auction. For example, if the revenues of the project are costly to verify, we know from Townsend (1979) that it is optimal for the party who observes the cash flows to be the residual claimant. Thus, if

\footnotetext{
${ }^{39}$ This is a special case of Lacker and Weinberg's (1989) model of "costly state falsification."

${ }^{40}$ Similarly, if the seller can divert cash flows, the constraint becomes $S^{\prime}(z) \geq \delta$, which rules out cash or debt and enhances revenues. Other moral hazard settings can also be considered. If the winner can add arbitrary risk (see, e.g., Ravid and Spiegel (1997)), then bidders are restricted to using convex securities, enhancing revenues.
} 
the seller observes the cash flows, the optimal agency contract is a call option, which also maximizes the auction revenues. If the winner observes the cash flows, there is a tradeoff between verification costs, which are minimized with debt securities, and auction revenues.

For mergers and acquisitions, tax implications and accounting treatment are likely to be important. For example, the deferral of taxes possible with an equity-based transaction may give rise to the use of equity bids even in an unrestricted setting. Our results imply that this tax preference can also lead to enhanced revenues for the seller.

It would be useful to allow for more complicated information structures. For example, bidders may have private information not only about $V$ but also about $X$, or the seller may have private information. Another extension of our model that would be useful in applications would be to allow for asymmetries in bidders' valuations and costs. We believe that our result showing that debt is the outcome for the informal auction generalizes to this setting. However, for formal mechanisms, we are confronted with the relative lack of theoretical results in the presence of asymmetries, even in the case of cash auctions.

\section{Appendix}

Proof of Lemma 1: Using Assumption B and the fact that $S(z)$ is between 0 and $z$, dominated convergence implies that the derivatives exist and are equal to $E S^{\prime}(v)=\int S(z) h_{v}(z \mid v) d z$ and $E S{ }^{\prime \prime}(v)=\int S(z) h_{v v}(z \mid v) d z$. Then, for any $z^{*}$,

$$
E S^{\prime}(v)=\int S(z) h_{v}(z \mid v) d z=\int\left[S(z)-S\left(z^{*}\right)\right]\left[\frac{h_{v}(z \mid v)}{h(z \mid v)}\right] h(z \mid v) d z,
$$

since $\int S\left(z^{*}\right) h_{v}(z \mid v) d z=S\left(z^{*}\right) \frac{\partial}{\partial v} \int h(z \mid v) d z=0$.

From SMLRP, $\left[h_{v} / h\right]$ is increasing in $z$. Therefore, we can choose $z^{*}$ so that

$$
\left[\frac{h_{v}(z \mid v)}{h(z \mid v)}\right]>0 \text { if and only if } \quad z<z^{*} .
$$

Then, since $S$ is weakly increasing,

$$
\left[S(z)-S\left(z^{*}\right)\right]\left[\frac{h_{v}(z \mid v)}{h(z \mid v)}\right] \geq 0,
$$

and the inequality is strict for $z$ such that $S(z) \neq S\left(z^{*}\right)$. This set has positive measure since $S \neq 0$ and $Z$ has full support conditional on $v$. Hence, $E S^{\prime}(v)>0$. The proof of $E S^{\prime}(v)<1$ is identical, substituting $Z-S(Z)$ for $S$.

Proof of Lemma 2: The proof that $s(v)$, which solves $E S(s, v)=v$, is the unique weakly undominated strategy is standard. Differentiating $E S(s(v), v)=v$ yields,

$$
s^{\prime}(v)=\frac{\frac{\partial}{\partial v}[v-E S(s, v)]}{\frac{\partial}{\partial s} E S(s, v)} .
$$


Thus $s$ increasing in $v$ follows, since $E S$ is increasing in $s$, and from Lemma 1, $\frac{\partial}{\partial v}[v-E S(s, v)]>0$ as long as $S(s, Z) \neq Z$ (which is not possible in equilibrium since $X>$ $0)$.

Proof of Lemma 3: Let $P(s)$ be the probability of winning with a bid of $s$, and $\pi(s, v)=$ $\log (P(s))+\log (v-E S(s, v))$. Then

$$
s(v) \in \arg \max _{s} P(s)(v-E S(s, v))=\arg \max _{s} \pi(s, v) .
$$

By Assumption $\mathrm{C}$ the objective in the second expression is strictly supermodular, and so by Topkis (1978), any selection $s(v)$ is weakly increasing in $v$. If $s(v)$ were constant on an interval, then the highest type in that interval can increase his bid marginally and increase his probability of winning, and thus his payoff, by a discrete amount. Thus, $s(v)$ is increasing. This implies $P(s(v))=F_{n}(v) \equiv F(v)^{n-1}$.

Continuity of $s$ follows since otherwise a type just above a discontinuity could gain by lowering his bid. For differentiability, note that we can rewrite the bidder's optimality condition as

$$
v \in \arg \max _{v^{\prime}} F_{n}\left(v^{\prime}\right)\left(v-E S\left(s\left(v^{\prime}\right), v\right)\right) .
$$

Letting $u(s, v)=v-E S(s, v)$, this implies that for any $v^{\prime}>v$,

$$
F_{n}(v) u(s(v), v) \geq F_{n}\left(v^{\prime}\right) u\left(s\left(v^{\prime}\right), v\right)=F_{n}\left(v^{\prime}\right)\left[u(s(v), v)+u_{1}\left(s^{*}, v\right)\left(s\left(v^{\prime}\right)-s(v)\right)\right],
$$

for some $s^{*}$ between $s(v)$ and $s\left(v^{\prime}\right)$. Since $u_{1}<0$, this can be rewritten as

Changing the roles of $v$ and $v^{\prime}$ yields, for some $s^{* *}$ between $s(v)$ and $s\left(v^{\prime}\right)$,

$$
\frac{F_{n}\left(v^{\prime}\right)-F_{n}(v)}{v^{\prime}-v} \times \frac{u\left(s\left(v^{\prime}\right), v^{\prime}\right)}{-F_{n}(v) u_{1}\left(s^{* *}, v^{\prime}\right)} \geq \frac{s\left(v^{\prime}\right)-s(v)}{v^{\prime}-v} .
$$

Taking limits establishes the differential equation for $s$.

For the boundary condition, note that $P\left(s\left(v_{L}\right)\right)=0$, and since all types earn non-negative profits $E S\left(s\left(v_{L}\right), v_{L}\right) \leq v_{L}$. But if the inequality were strict, the lowest type could raise his bid and earn positive profits with positive probability.

Having established uniqueness, it remains to verify existence by establishing the sufficiency of the bidder's first order condition. Consider any $s^{\prime}$ such that $s\left(v_{L}\right)<s^{\prime}<$ $s(v)$. There exists $v_{L}<v^{\prime}<v$ such that $s\left(v^{\prime}\right)=s^{\prime}$. Thus, by Assumption C,

$$
\pi_{s}\left(s^{\prime}, v\right)>\pi_{s}\left(s^{\prime}, v^{\prime}\right)=0 \text {. }
$$

A similar argument shows that for $s(v)<s^{\prime}<s\left(v_{H}\right), \pi_{s}\left(s^{\prime}, v\right)<0$. Hence, $\pi$ is quasiconcave in $s$ and the first order condition is sufficient.

Proof of Lemma 4: Using the revelation principle, note that if type $v$ reports $v^{\prime}$ he will win with probability $F^{n-1}\left(v^{\prime}\right)$. His expected payoff conditional on winning is equal to $(v$ $\left.-T\left(v, v^{\prime}\right)\right)$, where $T\left(v, v^{\prime}\right)$ is the expected payment by type $v$ when he reports $v^{\prime}$. Thus, 
type $v$ will choose $v^{\prime}$ to maximize $F^{n-1}\left(v^{\prime}\right)\left(v-T\left(v, v^{\prime}\right)\right)$. Thus, we need to establish the correct form for $T$.

Letting $V_{-i}^{*}$ be the highest type excluding $i$, bidder $i$ wins with report $v^{\prime}$ if $V_{-i}^{*}<v^{\prime}$. Let $\tilde{S}_{v^{\prime}} \in S$ be the random security that he will pay if he wins. Then define

$$
\hat{S}_{v^{\prime}}(z)=E\left[\tilde{S}_{v^{\prime}}(z) \mid V_{-i}^{*} \leq v^{\prime}\right],
$$

a security in the convex hull of $\boldsymbol{S}$ (which does not depend on $i$ by symmetry). This is the "expected security" paid with a report of $v^{\prime}$. Using the fact that types are independent and that $Z_{i}$ and $V_{-i}$ are independent given $V_{i}$ (private values), we then have that:

$$
\begin{aligned}
T\left(v, v^{\prime}\right) & =E\left[\tilde{S}_{v^{\prime}}\left(Z_{i}\right) \mid V_{i}=v, V_{-i}^{*} \leq v^{\prime}\right] \\
& =E\left[E\left[\tilde{S}_{v^{\prime}}\left(Z_{i}\right) \mid Z_{i}, V_{i}=v, V_{-i}^{*} \leq v^{\prime}\right] \mid V_{i}=v, V_{-i}^{*} \leq v^{\prime}\right] \\
& =E\left[E\left[\tilde{S}_{v^{\prime}}\left(Z_{i}\right) \mid Z_{i}, V_{-i}^{*} \leq v^{\prime}\right] \mid V_{i}=v, V_{-i}^{*} \leq v^{\prime}\right] \\
& =E\left[\hat{S}_{v^{\prime}}\left(Z_{i}\right) \mid V_{i}=v, V_{-i}^{*} \leq v^{\prime}\right] \\
& =E \hat{S}_{v^{\prime}}(v)
\end{aligned}
$$

This completes the proof.

Proof of Lemma 5: Let $G(z)=S_{1}(z)-S_{2}(z)$. Then if $E G\left(v^{*}\right)=0$,

$$
\begin{aligned}
E G^{\prime}\left(v^{*}\right) & =\int G(z) h_{v}\left(z \mid v^{*}\right) d z=\int G(z)\left[\frac{h_{v}\left(z \mid v^{*}\right)}{h\left(z \mid v^{*}\right)}\right] h\left(z \mid v^{*}\right) d z \\
& =\int G(z)\left[\frac{h_{v}\left(z \mid v^{*}\right)}{h\left(z \mid v^{*}\right)}-\frac{h_{v}\left(z^{*} \mid v^{*}\right)}{h\left(z^{*} \mid v^{*}\right)}\right] h\left(z \mid v^{*}\right) d z
\end{aligned}
$$

where the last equality follows since

$$
\int G(z) \frac{h_{v}\left(z^{*} \mid v^{*}\right)}{h\left(z^{*} \mid v^{*}\right)} h\left(z \mid v^{*}\right) d z=\frac{h_{v}\left(z^{*} \mid v^{*}\right)}{h\left(z^{*} \mid v^{*}\right)} E G\left(v^{*}\right)=0 .
$$

From SMLRP, $\left[h_{v} / h\right]$ is increasing in $z$. Therefore,

$$
G(z)\left[\frac{h_{v}\left(z \mid v^{*}\right)}{h\left(z \mid v^{*}\right)}-\frac{h_{v}\left(z^{*} \mid v^{*}\right)}{h\left(z^{*} \mid v^{*}\right)}\right] \geq 0
$$

and the inequality is strict on the set $\left\{z: S_{1}(z) \neq S_{2}(z)\right\}$. Thus, $E G^{\prime}\left(v^{*}\right)>0$.

Proof of Proposition I: Consider a second-price auction. From Lemma 2, the winner is the highest type, $V^{1}$, and pays the second highest security bid by the second highest type, $V^{2}$. Let $S_{1}$ be the security bid by type $V^{2}$ under $S_{1}$ and $S_{2}$ be the security bid by type $V^{2}$ under $S_{2}$. Since $E S(s(v), v)=v$ in a second-price auction, $V^{2}=E S_{1}\left(V^{2}\right)=E S_{2}\left(V^{2}\right)$. But then, since $S_{1}$ is steeper, $S_{1}$ strictly crosses $S_{2}$ from below and so $E S_{1}\left(V^{1}\right)>E S_{2}\left(V^{1}\right)$. Thus, the seller's expected revenues are higher under $\boldsymbol{S}_{\boldsymbol{1}}$. 
For the first-price auction, let $U^{j}(v)$ be the equilibrium payoff for type $v$, and $S_{v}^{j}$ the security bid, with the set $S_{j}$. First, note that efficiency implies $U^{1}\left(v_{L}\right)=U^{2}\left(v_{L}\right)=0$. Since

$$
U^{j}(v) \equiv \max _{\hat{v}} F^{n-1}(\hat{v})\left(v-E S_{\hat{v}}^{j}(v)\right)=F^{n-1}(v)\left(v-E S_{v}^{j}(v)\right),
$$

if $U^{1}(v)=U^{2}(v)$, we have $E S_{v}^{1}(v)=E S_{v}^{2}(v)$. But if $\boldsymbol{S}_{\mathbf{1}}$ is steeper than $\boldsymbol{S}_{2}$, $E S_{v}^{1}{ }^{\prime}(v)>E S_{v}^{2}{ }^{\prime}(v)$. Thus, from the envelope condition,

$$
U^{1}{ }^{\prime}(v)=F^{n-1}(v)\left(1-E S_{v}^{1}{ }^{\prime}(v)\right)<F^{n-1}(v)\left(1-E S_{v}^{2}{ }^{\prime}(v)\right)=U^{2}{ }^{\prime}(v) .
$$

Hence, $U^{1}(v)<U^{2}(v)$ for $v>v_{L}$. Since bidders' payoffs are lower, the seller's expected revenue is higher for each realization of the winning type under $\boldsymbol{S}_{\mathbf{1}}$.

Proof of Corollary to Proposition I: Since debt has slope 1 and then 0 , it strictly crosses any other non-debt security from above. Call options have slope 0 and then 1 , and so strictly cross any other non-option security from below. The result then follows directly from Proposition I.

What about the comparison of debt securities to other sets that may include debt? The proof for second-price auctions is unchanged. But for first-price auctions, we have the minor difficulty that a debt security does not strictly cross another debt security. In that case we modify the set of debt securities by adding $\varepsilon$ in cash - i.e., the security payoff is $S(z)=\min (z, d)+\varepsilon$. This set strictly crosses any other set from above, and so the revenues can be ranked as in PROPOSITION I. The result then follows from the continuity of the equilibrium strategies and payoffs in the first-price auction as we take the limit as $\varepsilon$ $\rightarrow 0$. We can do the same for call options by subtracting cash $\varepsilon$ from each security.

Proof of Lemma 6: For debt securities, consider any feasible security $S_{2}$. If $S_{2}(z)>$ $\min (d, z)$, then $z>d$ and so $S_{2}\left(z^{\prime}\right)>\min \left(d, z^{\prime}\right)$ for all $z^{\prime}>z$. Hence $\min (d, z)$ crosses $S_{2}$ from above.

For levered equity, note that a convex combination of these securities for different levels of leverage is a security $S_{2}(z)$ that is convex in $z$ with maximum slope $\alpha$. Thus, any levered equity security crosses $S_{2}$ from below. A similar argument applies to call options, and to convertible debt when indexed by the equity share $\alpha$.

Proof of Proposition II: Consider the direct revelation game corresponding to the two auctions. Let $S_{v}^{1}$ be the security bid in the first-price auction, and let $S_{v}^{2}$ be the expected security payment in the second-price auction for a winner with type $v$, defined according to (8) in the proof of Lemma 4. Then, if the set of securities is super-convex, $S_{v}^{1}$ crosses $S_{v}^{2}$ from below, and a nearly identical argument to that used in the proof of Proposition I for first-price auctions can be applied to prove that the seller's expected revenues are higher in the first-price auction.

The only complication is that the securities issued by the lowest types are identical in the first and second-price auctions, so that the securities do not strictly cross and $U^{1}{ }^{\prime}\left(v_{L}\right)=U^{2}{ }^{\prime}\left(v_{L}\right)$. To resolve this, we can change the support in the first-price auction to $\left[v_{L}+\varepsilon, v_{H}\right]$, with an atom at $v_{L}+\varepsilon$ with mass equal to that originally on the set $\left[v_{L}, v_{L}+\varepsilon\right]$. 
Now, $U^{1}\left(v_{L}+\varepsilon\right)=0<U^{2}\left(v_{L}+\varepsilon\right)$, and by the same argument as in the proof of Proposition I, $U^{1}(v)<U^{2}(v)$ for all $v \geq v_{L}+\varepsilon$. Then by the continuity of the strategies and payoffs in the boundary of the support $v_{L}+\varepsilon$, the first-price auction has weakly higher revenues. However, since the securities strictly cross for higher types, the revenues cannot be equal.

The proof for sub-convex sets is identical, with the inequalities reversed (and taking the limit of the support for the second-price auction).

Proof of Proposition III: In a GSM, the winner pays according to a random security. From Lemma 4 , the expected payment by type $v$ reporting $v^{\prime}$ can be written as $E \hat{S}_{v^{\prime}}(v)$, where $\hat{S}_{v^{\prime}}$ is in the convex hull of the ordered set of securities $S$. Since $S$ is convex, we can define $s^{*}\left(v^{\prime}\right)$ such that

$$
S\left(s^{*}\left(v^{\prime}\right), \cdot\right)=\hat{S}_{v^{\prime}}(\cdot) \text {. }
$$

Because $S$ is ordered, incentive compatibility implies $s^{*}(v)$ must be increasing; otherwise a bidder could raise the probability of winning without increasing the expected payment. Thus, $s^{*}(v)$ defines an efficient equilibrium for the first-price auction. The result then follows from the uniqueness of equilibrium in the first-price auction.

Proof of Proposition V: We focus on the no-cash case as the argument with cash is similar (and even simpler as off-equilibrium beliefs do not play any major role). In step 1 we show existence of a debt-based equilibrium that survives the D1 refinement. In steps 2 and 3 we show that no other equilibrium exists. In step 2 we prove that any equilibrium is equivalent to the equilibrium of a first-price auction in debt contracts. The logic is that, by D1, a deviation to a debt contract with the same cost as the original equilibrium bid cannot decrease the probability of winning. Therefore such a debt bid is also optimal and we can construct a payoff-equivalent equilibrium in which only debt is used. In step 3, we use the envelope condition to argue that the securities used in the original equilibrium must have slopes equal to debt contracts. But we know from Lemma 5 that debt is flatter than any non-debt security, so the original securities must have been debt as well. Finally, we invoke Lemma 3 that states uniqueness of symmetric equilibrium in debt contracts.

The proof differs somewhat from the intuition in the text, which considers deviations by type $v$ to mimic type $v^{\prime}=v-d v$. This "local deviation" is more intuitive, but is not precise since types are not discrete and therefore there is no nearby type $v^{\prime}$ that type $v$ is truly indifferent towards mimicking. With continuous types, we first show that type $v$ is indifferent to switching to debt (without mimicking another type) in step 2, and then show in step 3 that if the original equilibrium were not debt, because debt is flatter there must be a profitable deviation.

STEP 1: The equilibrium from a first-price debt auction is a D1 equilibrium in the unrestricted auction (with appropriate off-equilibrium beliefs).

We need to demonstrate that given the strategies from the debt auction, there is a set of beliefs satisfying D1 that support this equilibrium in the unrestricted auction. We construct the beliefs $R$ using (5) and (7). If (7) does not produce a unique score, we can choose the lowest one. We now show that this supports the equilibrium. 
STEP 1A: For debt contracts, the score is increasing in the face value of the debt. That is, $R\left(S^{d}\right)$ is increasing in $d$, where $S^{d}(z)=\min (d, z)$.

Note that

$$
\arg \min _{v} B\left(S^{d}, v\right)=\arg \max _{v} \frac{v-E S^{d}(v)}{U(v)} .
$$

Because the objective function is strictly log-supermodular by Assumption $\mathrm{C}$, from Topkis (1978) we know that $v$ is weakly increasing with $d$. Thus, (7) implies $R\left(S^{d}\right)$ is increasing in $d$.

STEP 1B: $R$ supports an equilibrium in the unrestricted auction.

Consider any deviation to a debt contract. From Step 1a, the probability of winning the auction is the same as in a first-price auction. Since we have a first-price equilibrium, there is no gain to the deviation.

Consider a deviation to a non-debt contract $S$. To show it is not profitable for any type, we must show that $P(R(S)) \leq \min _{v} B(S, v)$. Let $v$ be the highest type in the set that minimizes $B(S, v)$. Then $E S(v) \geq R(S)$. It is sufficient to show that type $v$ does not find the deviation to $S$ profitable; i.e. to show that $P(R(S)) \leq B(S, v)$.

Find $d$ such that $E S^{d}(v)=E S(v)$. Then $B\left(S^{d}, v\right)=B(S, v)$. From Lemma 5, types $v^{\prime}<v$ find $S^{d}$ more expensive than $S$, so that $B\left(S^{d}, v^{\prime}\right)>B\left(S, v^{\prime}\right) \geq B(S, v)$. Therefore, $\arg \min _{v^{\prime}} B\left(S^{d}, v^{\prime}\right) \geq v$, and so from (7),

$$
R\left(S^{d}\right) \geq E S^{d}(v) \geq R(S) .
$$

Thus, if a deviation to $S$ is profitable, so is a deviation to $S^{d}$. But this contradicts the fact that no deviation to a debt contract is profitable.

STEP 2: A symmetric D1 equilibrium in the unrestricted auction has the same payoffs as the equilibrium of a first-price debt auction.

Our method of proof is to show that any non-debt bids can be replaced with an equivalent debt bid without changing the equilibrium.

STEP 2A: If $S$ is not a debt contract, then at most one type uses this security.

Suppose not, so that $v_{1}<v_{2}$ are the lowest and highest types that use $S$. Then, by (5), $R(S)$ $=E S\left(v^{*}\right)$ for some $v_{1}<v^{*}<v_{2}$. Consider the debt contract $S^{d}$ with the same cost for type $v^{*}$; i.e. such that $E S^{d}\left(v^{*}\right)=E S\left(v^{*}\right)$. From Lemma 5, types $v<v^{*}$ find the $S^{d}$ more expensive than $S$, so that $B\left(S^{d}, v\right)>P(R(S))$. Therefore, $\arg \min _{v} B\left(S^{d}, v\right) \geq v^{*}$. Thus, from (7), $R\left(S^{d}\right) \geq E S^{d}\left(v^{*}\right)=R(S)$. But this contradicts an equilibrium, as type $v_{2}$ finds $S^{d}$ strictly cheaper than $S$ with a weakly higher score.

STEP 2B: Suppose type $v$ uses contract $S$, and define $d(v)$ as the debt level that for type $v$ has equal cost; i.e., $E S^{d(v)}(v)=E S(v)$. Then bidding $S^{d(v)}$ has the same payoff as bidding $S$, and so $S^{d(v)}$ is also optimal for type $v$.

Because $S$ is an equilibrium bid, $P\left(R\left(S^{d(v)}\right)\right) \leq P(R(S))$ by (6). However, by the same argument used in the previous step, lower types find $S^{d(v)}$ more costly than $S$ so that 
$B\left(S^{d(v)}, v^{\prime}\right)>P(R(S))$ for $v^{\prime}<v$. Hence $R\left(S^{d(v)}\right) \geq E S^{d(v)}(v)=R(S)$. Thus, $P\left(R\left(S^{d(v)}\right)\right)=$ $P(R(S))$. The result follows since the cost and probability of acceptance of bidding debt with face value $d(v)$ and bidding $S$ are the same for type $v$.

STEP 2C: $d(v)$ is the unique symmetric equilibrium for a first-price auction restricted to debt and it is increasing.

From Step $2 \mathrm{~b}$, bidding debt $d(v)$ is optimal and so solves

$$
U(v)=P\left(R\left(S^{d(v)}\right)\right)\left(v-E S^{d(v)}(v)\right)=\max _{d} P\left(R\left(S^{d}\right)\right)\left(v-E S^{d}(v)\right) .
$$

Using the same logic as in step $1 \mathrm{a}, R\left(S^{d}\right)$ is increasing in $d$. Therefore, this maximization problem is identical to the problem faced by bidders in a debt-only first-price auction. Uniqueness and monotinicity follow from Lemma 3.

STEP 3: In a symmetric D1 equilibrium in the unrestricted auction, almost every bid is a debt contract.

From Step 2 and Lemma 3, the equilibrium payoff of type $v$ in the first-price auction with debt is

$$
U(v)=F^{n-1}(v)\left(v-E S^{d(v)}(v)\right),
$$

and so $U$ is differentiable. Suppose type $v \in\left(v_{L}, v_{H}\right)$ bids $S$ in equilibrium. Then by a standard envelope argument,

$$
U^{\prime}(v)=F^{n-1}(v)\left(1-E S^{\prime}(v)\right) .
$$

Thus, $E S(v)=E S^{d(v)}(v)$ and $E S^{\prime}(v)=E S^{d(v)^{\prime}}(v)$. Therefore by Lemma 5, $S=S^{d(v)}$.

\section{Proof of Proposition VI:}

\section{Case 1: First and Second-Price Auctions}

Let $s^{\prime}$ be a bid that wins with positive probability such that $S\left(s^{\prime}, 0\right)<0$. Then, due to the moral hazard problem, submitting this bid earns strictly positive profits for any type, since any type can simply not invest and collect $-S\left(s^{\prime}, 0\right)$ in a first-price auction, or even more in a second-price auction (since the second highest bid is below $s^{\prime}$ ). Thus, by incentive compatibility, all equilibrium bids earn positive profits.

Let $\underline{s}$ be the lowest bid submitted. Then the above implies this bid must win with positive probability. Since it is the lowest bid, this implies a tie -- that is, $\underline{s}$ is submitted with positive probability. But then raising the bid slightly would lead to a discrete jump in the probability of winning and hence in profits.

Incentive compatibility therefore implies $\underline{s}=s_{1}$, the highest possible bid. If $S\left(s_{1}, 0\right) \geq 0$, this contradicts the existence of $s^{\prime}$. If $S\left(s_{1}, 0\right)<0$, then all types bid $s_{1}$. But at $s_{1}$, all types lose money if they run the project. Therefore, all types bid $s_{1}$, do not invest, and collect $-S\left(s_{1}, 0\right)>0$ from the seller.

Case 2: General Mechanisms

In an efficient mechanism, the lowest type wins with zero probability and so earns zero expected profits. Since lowest type can claim to be any type and not invest, it must be the 
case that no type with positive probability of winning pays a security with $S(0)<0$ with positive probability.

Case 3: Informal Auctions

Here the result follows immediately from our result that an equilibrium will always use the flattest possible securities. If $S(0)<0$, we can "flatten" the security by raising $S(0)$ and flattening it elsewhere.

\section{Proof of Results in Section 5.3:}

Result 1: Consider a first-price auction and two sets of securities $A$ and $B$ where $A$ is steeper than $B$. Let $S_{v}^{A}$ and $S_{v}^{B}$ be the equilibrium bid for type $v$ using these two sets. Consider the expected payments of a type $v$ who bids as type $v^{\prime}$ :

$$
M^{j}\left(v, v^{\prime}\right)=E\left[S_{v^{\prime}}^{j}\left(Z_{i}\right) \mid V_{i}=v, V_{-i}^{*} \leq v^{\prime}\right] \text { for } j=A, B \text {. }
$$

Suppose $M^{A}(v, v)=M^{B}(v, v)$. Given affiliation, a direct generalization of Lemma 5 implies that $M_{1}^{A}(v, v)>M_{1}^{B}(v, v)$. The conclusion then follows from the same linkage principle argument as in the proof of Proposition I.

Now consider a second-price auction. The equilibrium bid satisfies the zero profit condition:

$$
E\left[S_{v}^{j}\left(Z_{i}\right) \mid V_{i}=v, V_{-i}^{*}=v\right]=E\left[Z_{i}-X \mid V_{i}=v, V_{-i}^{*}=v\right]
$$

The proof follows the same logic as in Proposition I; the seller's revenues depend on the set of securities through the difference

$$
E\left[S_{v_{2}}^{j}\left(Z_{i}\right) \mid V_{i}=v_{1}, V_{-i}^{*}=v_{2}\right]-E\left[S_{v_{2}}^{j}\left(Z_{i}\right) \mid V_{i}=v_{2}, V_{-i}^{*}=v_{2}\right]
$$

Again, affiliation implies this difference will be larger for steeper securities.

Result 2: Consider a set $A$ of securities that is convex or sub-convex. Let $S_{v}^{j}$ be the bid of type $v$ in a $j$-price auction. The expected payment for type $v$ who bids as $v^{\prime}$ in a firstprice auction is

$$
M^{1}\left(v, v^{\prime}\right)=E\left[S_{v^{\prime}}^{1}\left(Z_{i}\right) \mid V_{i}=v, V_{-i}^{*} \leq v^{\prime}\right]=E\left[S_{v^{\prime}}^{1}\left(Z_{i}\right) \mid V_{i}=v\right]
$$

where the second equality follows from the private value assumption. For a second-price auction,

$$
M^{2}\left(v, v^{\prime}\right)=E\left[S_{V_{-i}^{*}}^{2}\left(Z_{i}\right) \mid V_{i}=v, V_{-i}^{*} \leq v^{\prime}\right]=E\left[S_{v, v^{\prime}}^{2}\left(Z_{i}\right) \mid V_{i}=v\right]
$$

where $S_{v, v^{\prime}}^{2}(z)=E\left[S_{V_{-i}^{*}}^{2}(z) \mid V_{i}=v, V_{-i}^{*} \leq v^{\prime}\right]$ for all $z$; the security $S_{v, v^{\prime}}^{2}$ is in the convex hull of $A$. Suppose $M^{1}(v, v)=M^{2}(v, v)$. To apply the linkage principle, we must show that $M_{1}^{1}(v, v)<M_{1}^{2}(v, v)$. But this follows since (i) $S_{v, v}^{2}$ is in the convex hull of $A$ and 
therefore is steeper than $S_{v}^{1}$, and (ii) affiliation and the monotonicity of bids implies that $E\left[S_{v, v^{\prime}}^{2}\left(Z_{i}\right) \mid V_{i}=v^{\prime \prime}\right]$ is increasing in $v$.

Result 3: Let $\alpha^{j}(v)$ be the equity bid of type $v$ in a j-price auction. Then

$$
\begin{aligned}
M^{1}\left(v, v^{\prime}\right) & =E\left[\alpha^{1}\left(v^{\prime}\right) Z \mid V_{i}=v, V_{-i}^{*} \leq v^{\prime}\right]=\alpha^{1}\left(v^{\prime}\right) E\left[Z \mid V_{i}=v, V_{-i}^{*} \leq v^{\prime}\right] \\
M^{2}\left(v, v^{\prime}\right) & =E\left[\alpha^{2}\left(V_{-i}^{*}\right) Z \mid V_{i}=v, V_{-i}^{*} \leq v^{\prime}\right] \\
& >E\left[\alpha^{2}\left(V_{-i}^{*}\right) \mid V_{-i}^{*} \leq v^{\prime}\right] E\left[Z \mid V_{i}=v, V_{-i}^{*} \leq v^{\prime}\right]
\end{aligned}
$$

where the inequality follows since $\alpha^{2}\left(V_{-i}^{*}\right)$ and $Z$ are positively correlated, and we use the fact that types are independent. Therefore, $M^{1}\left(v, v^{\prime}\right)=M^{2}\left(v, v^{\prime}\right)$ implies that

$$
\alpha^{1}\left(v^{\prime}\right)>E\left[\alpha^{2}\left(V_{-i}^{*}\right) \mid V_{-i}^{*} \leq v^{\prime}\right]
$$

But since $E[Z \mid V]=\sum_{l} V_{l}$,

$$
M_{1}^{1}\left(v, v^{\prime}\right)=\alpha^{1}\left(v^{\prime}\right)>M_{1}^{2}\left(v, v^{\prime}\right)=E\left[\alpha^{2}\left(V_{-i}^{*}\right) \mid V_{i}=v, V_{-i}^{*} \leq v^{\prime}\right]
$$

Thus, the result follows from the linkage principle.

\section{References}

Binmore, K. and P. Klemperer (2002), "The Biggest Auction Ever: The Sale of the British 3G Telecom Licenses,” Economic Journal, 112, 74-96.

Board S. (2002) "Bidding into the Red," working paper, University of Toronto.

Board S. (2004) "Selling Options," working paper, University of Toronto.

Bulow, J. and P. Klemperer (2002), "Prices and the Winner's Curse," Rand Journal of Economics, 33, 1-21.

Che, Y.K. and I. Gale (2000) "The Optimal Mechanism for Selling to a BudgetConstrained Buyer," Journal of Economic Theory, 92, 198-233.

Cho, I. K. and D. M. Kreps (1987): "Signaling Games and Stable Equilibria," Quarterly Journal of Economics, 102, 179-221.

Cho, I. K., and J. Sobel (1990): "Strategic Stability and Uniqueness in Signaling Games," Journal of Economic Theory, 50, 381-413.

Cremer, J. (1987): “Auctions with Contingent Payments: Comment," American Economic Review, 77 (4), 746.

DeMarzo, P. (2002): "Portfolio Liquidation and Security Design with Private Information," working paper. 
DeMarzo, P. and D. Duffie (1999): "A Liquidity Based Model of Security Design," Econometrica, 67, 65-99.

Fisch, J. (2001) "Aggregation, Auctions and Other Developments in the Selection of Lead Counsel Under the PSLRA," Law and Contemporary Problems, Vol. 64, No. 2. Garmaise, M. (2001): "Informed Investors and the Financing of Entrepreneurial Projects," working paper, UCLA.

Garmaise (2001) "Informed Investors and the Financing of Entrepreneurial Projects," working paper, University of Chicago.

Hansen, R. G. (1985): “Auctions with Contingent Payments," American Economic Review, 75 (4), 862-65.

Hart, O., and Moore, J. (1995). "Debt and seniority - an analysis of the role of hard claims in constraining management," American Economic Review, vol. 85, 567585.

Hendricks, K. and R. Porter (1988). "An Empirical Study of an Auction with Asymmetric Information," American Economic Review, Vol. 78, No. 5, 865-83.

Kohlberg, E. and J. F. Mertens (1986): "On the Strategic Stability of Equilibria," Econometrica, 54 (5), 1003-38.

Krishna, V. (2002): Auction Theory, San Diego: Academic Press.

Lacker, J. M. and J.A.Weinberg (1989): "Optimal Contracts under Costly State Falsification," Journal of Political Economy, 97 (6), 1345-63.

Laffont, J. J. and J. Tirole (1987): “Auctioning Incentive Contracts," Journal of Political Economy, 95 (5), 921-37.

Martin, K. J. (1996): "The Method of Payment in Corporate Acquisitions, Investment Opportunities, and Management Ownership," Journal of Finance, 51(4), pp. 1227-1246.

Maskin, E. and J. Riley (1984): "Optimal Auctions with Risk Averse Buyers," Econometrica, 52 (6), 1473-1518.

McAfee, P. R. and J. McMillan (1987): "Competition for Agency Contracts," Rand Journal of Economics, 18 (2), 296-307.

McMillan, J. (1991): "Bidding for Olympic Broadcast Rights: The Competition before the Competition," Negotiation Journal, July 255-263.

Milgrom, P. R. and R. J. Weber (1982): "A Theory of Auctions and Competitive Bidding," Econometrica, 50 (5), 1089-1122.

Myerson, R. B. (1981): "Optimal auction design," Mathematics of Operations Research, $6(1), 58-73$.

Nachman, D. and T. Noe (1994): "Optimal Design of Securities under Asymmetric Information," Review of Financial Studies, 7, 1-44.

Ramey, G. (1996). "D1 Signaling Equilibria with Multiple Signals and a Continuum of Types," Journal of Economic Theory, 69: 508-531. 
Ravid, S. A. and M. Spiegel (1997): "Optimal Financial Contracts for a Start-Up with Unlimited Operating Discretion," Journal of Financial and Quantitative Analysis, 32, No. 3, 269-286.

Rhodes-Kropf, M. and S. Viswanathan (2000): "Corporate Reorganizations and Non-cash Auctions," Journal of Finance, 55 (4), 1807-49.

Rhodes-Kropf, M. and S. Viswanathan (2002): "Financing Auction Bids," working paper.

Riley, J. G. (1988): "Ex post Information in Auctions," Review of Economic Studies, 55 (3), 409-29.

Riley, J. G. and W. F. Samuelson (1981): “Optimal auctions,” American Economic Review, 71, 381-392.

Samuelson, W. (1987): “Auctions with Contingent Payments: Comment,” American Economic Review, 77, 740-745.

Topkis, D. M. (1978): "Minimizing a Submodular Function on a Lattice," Operations Research, 26, 305-321.

Townsend, R. (1979): “Optimal contracts and competitive markets with costly state verification," Journal of Economic Theory, 21, 265-293.

Vickrey, W. (1961): "Counterspeculation, Auctions, and Competitive Sealed Tenders," Journal of Finance, 16, 8-37.

Zheng C. (2001). "High Bids and Broke Winners." Journal of Economic Theory, 100, 129-171. 